\title{
Daniel Zuloaga y la decoración de portales: dos obras maestras de su producción
}

\author{
Daniel Zuloaga and the decoration of hallways: \\ two masterpieces of his production
}

\author{
María Teresa PALIZA MONDUATE \\ Universidad de Salamanca \\ ORCID: https://orcid.org/0000-0003-2330-304X / paliza@usal.es \\ DOI: http://dx.doi.org/10.18002/da.v0i18.5704
}

Recibido: 3-I-2019

Aceptado: 21-V-2019

RESUMEN: Este artículo aborda el estudio de los dos portales más relevantes diseñados por Daniel Zuloaga a lo largo de su práctica profesional. Corresponden a las casas de Nicolás Murga (1899) y Armando Otero (1916) de Bilbao. Pertenecen a la segunda y la última etapa del ceramista y ejemplifican muy bien la calidad de sus proyectos, así como las tendencias vigentes en la decoración de esos recintos a finales del siglo XIX y principios del XX. Asimismo dejan constancia del interés y esfuerzo de algunos promotores por realzar los zaguanes de sus inmuebles con una decoración singular realizada ad hoc.

Palabras claves: Ismael Bedia; Severino Achúcarro; Luis Aladrén; Bilbao; Mario Camiña; Cerámica; Jean Baptiste Darroqui; Portal; Siglo XX, Daniel Zuloaga.

ABSTRACT: This article approaches the study of the two most relevant hallways designed by Daniel Zuloaga over the course of his professional career. They belong to the houses of Nicolás Murga (1899) and Armando Otero (1916) in Bilbao. They are set in the second and final stage of the ceramist's career and are excellent examples of the quality of his projects as well as of the prevailing decorative trends for these spaces in the late nineteenth and early twentieth centuries. Likewise, they are proof of the interest and efforts that certain developers devoted to enhancing the entrance halls of their properties with a unique ad hoc decoration.

Keywords: Ismael Bedia; Severino Achúcarro; Luis Aladrén; Bilbao; Mario Camiña; Pottery; Jean Baptiste Darroqui; Hallway, Twentieth century; Daniel Zuloaga.

\section{INTRODUCCIÓN}

La biografía y la trayectoria de Daniel Zuloaga (1852-1921) son sobradamente conocidas, al igual que sus principales obras. No obstante, carecemos de investigaciones minuciosas de otras muchas, como las que aquí abordamos, que apenas han sido ob- jeto de atención por parte de los estudiosos ${ }^{1}$.

\footnotetext{
${ }^{1}$ La bibliografía sobre Daniel de Zuloaga es abundante. Su obra ha sido objeto de análisis en dos tesis doctorales a cargo de María Jesús Quesada y Abraham Rubio, especialistas que cuentan en su haber con importantes publicaciones sobre el ceramista. No obstante, dado lo prolífico de su producción y la diversidad e importancia de la misma, queda una labor
} 
Nacido en Madrid, su padre fue Eusebio Zuloaga, armero real y dueño de la fábrica de armas de Eibar (Guipúzcoa). Daniel tuvo talento para distintas disciplinas artísticas, ya que, aparte de ceramista, fue escultor, dibujante y pintó paisajes y retratos. Después de un período formativo en la Manufactura de Sèvres (Francia) a finales de los años sesenta, regresó a España y empezó su práctica profesional, en la que los especialistas establecen tres o cuatro etapas. La primera (1877-1892) corresponde a sus años en la Fábrica y Escuela de Cerámica de La Moncloa, donde trabajó con sus hermanos Guillermo y Germán. En esa fase desarrolló soluciones neorrenacentistas y orientalistas, siendo las obras más destacadas en lo tocante a la

ingente por hacer para conocer en detalle muchos de sus proyectos. Como bibliografía de referencia sobre este artista vid. María Jesús Quesada Martín, "Daniel Zuloaga (1852-1921)", Estudios Pro Arte, no 11 (1977), 76-84; Manuel Valdés Fernández, “Una cerámica de Zuloaga en León", en Estudios Humanísticos y Jurídicos: homenaje a Emilio Hurtado Llamas (León: Colegio Universitario de León, 1977), 387-395 y “Un aspecto del modernismo leonés: las cerámicas de Zuloaga", Estudios Humanísticos. Geografía, Historia, Arte, no 2 (1980), 99-107; María Jesús Quesada Martín, "Daniel Zuloaga. Ceramista y pintor" (tesis doctoral, Madrid, 1984); “Cerámica arquitectónica de Daniel Zuloaga en Madrid 1880-1900", Archivo Español de Arte, no 232 (1985), 369-378; Daniel Zuloaga 1852-1921 (Segovia: Caja de Ahorros y Monte de Piedad de Segovia, 1985) y "Daniel Zuloaga, ceramista (1852-1921)", en Los Zuloaga. Dinastía de artistas vascos, coord. por Ramón Suárez Zuloaga (Usurbil: Ramón Suárez Zuloaga, 1988), 129-181; Antonio Perla, Cerámica aplicada a la arquitectura madrileña (Madrid: TF, 1998); Abraham Rubio Celada, "De la tradición a la modernidad: Los Zuloaga ceramistas" (tesis doctoral, Madrid, 2004) y Los Zuloaga: artistas de la cerámica (Madrid: TF, 2007); Abraham Rubio Celada y Alonso Zamora Canellada, Ocharan, Zuloaga y El Quijote (Segovia: Caja Segovia, 2007); Maite Paliza Monduate, "La cerámica aplicada en la decoración de interiores en torno a 1900. El mural de la casa de Tomás Allende en Bilbao", BSAA. Arte, no 78 (2012), 237-260; Jorge Maier Allende y Abraham Rubio Celada, “La decoración de la galería de la casa de Tomás Allende en la calle Mayor de Madrid (1901). Otras obras de Daniel Zuloaga para la familia Allende", Además de: Revista on line de artes decorativas y diseño, $\mathrm{n}-2$ (2016), 89-111, enlace web. cerámica aplicada a la arquitectura las del Pabellón de la Exposición de Minería (1883) -hoy conocido como Pabellón Velázquez-, la Escuela de Ingenieros de Minas (1886) y el Pabellón Estufa de la Exposición de Filipinas (1887), también llamado Palacio de Cristal, todos en Madrid e ideados por el arquitecto Ricardo Velázquez Bosco (1843-1923). Durante la segunda (1893-1907) formó una sociedad con Marcos Vargas, propietario de la fábrica de loza La Segoviana de esa capital, instalando su taller dentro de las dependencias de esa factoría. En este período continuó utilizando formas neorrenacentistas, pero a partir de 1898 irrumpieron con fuerza en su producción el modernismo, el regionalismo y el realismo. Fueron los años en los que alcanzó su máxima proyección, llevando a cabo los revestimientos del Ministerio de Fomento (1893), también de Velázquez Bosco. En 1907 se estableció durante un breve lapso de tiempo en la localidad guipuzcoana de Pasajes para pasar poco después a la Iglesia de San Juan de los Caballeros de Segovia. Es el comienzo de su tercera época, en la que abandonó por completo el modernismo y que abarca hasta su fallecimiento en 1921. No obstante, algunos estudiosos dividen estos últimos años en dos períodos, separados por el estallido de la Primera Guerra Mundial, por lo que contemplan una cuarta fase ${ }^{2}$.

Su obra cerámica comprende dos campos, la aplicada a la arquitectura y todo tipo de objetos de pequeño formato de ese material. La mayoría de las piezas y los proyectos que diseñó a lo largo de casi seis décadas de práctica profesional se enmarcan dentro de lo que el arquitecto bilbaíno Enrique Epalza Chanfreau (1861-1930, titulado en 1886) gráficamente designó como cerámica de arte ${ }^{3}$,

${ }^{2}$ Rubio Celada establece tres períodos, mientras que Quesada Martín opta por cuatro. Rubio Celada, Los Zuloaga..., 14; Quesada Martín, “Daniel Zuloaga. Ceramista y pintor...", T. I, 84-140 y Daniel Zuloaga..., 43-61.

${ }^{3}$ Utilizó esta expresión en una carta, dirigida a Daniel Zuloaga el cinco de abril de 1904, relacionada con los revestimientos cerámicos de las fachadas de la casa de vecindad que había diseñado poco antes para 
aunque de su establecimiento también salieron azulejos seriados, mucho más económicos y ajenos al terreno artístico propiamente dicho.

Por lo que atañe a la tipología de la vivienda, aparte de revestimientos para fachadas, elaboró chimeneas, alacenas, frisos para patios, terrazas, galerías, vestíbulos y escaleras principalmente. De todos modos, la mayoría de estos encargos correspondieron a residencias unifamiliares. De hecho lo habitual en las casas de vecindad fueron las chimeneas y en menor medida los murales para portales. Con respecto a los últimos, a juzgar por los datos con los que contamos hoy día, consta que solo realizó cinco -tres en la capital de España, dos en Bilbao- ${ }^{4}$, es decir que no se prodigó especialmente en esta parcela, a diferencia de lo que ocurrió con los exteriores de este tipo de inmuebles para los que diseñó numerosos revestimientos.

Los dos zaguanes de Bilbao se enmarcan dentro de la profunda transformación urbanística y arquitectónica experimentada por la ciudad en las últimas décadas del siglo XIX y las primeras del XX como consecuencia del desarrollo industrial y el consiguiente crecimiento demográfico. Dentro de ese contexto la construcción de casas de vecindad sufrió un notable incremento. En su mayor parte, las erigidas en los últimos decenios de la centuria decimonónica fueron resueltas acorde a los postulados del eclecticismo, corriente que pervivió en los primeros años del pasado siglo, aunque poco a poco se abrieron camino el modernismo y el regionalismo. La

Eulalio Arana en Bilbao. Quesada Martín, “Daniel Zuloaga. Ceramista y pintor...", T. II, 364.

${ }^{4}$ En la ciudad de León existe una obra que, aunque a día de hoy corresponde a portal de una casa de vecindad, no puede ser computada como tal, dado que se trata de un edificio que fue diseñado como vivienda unifamiliar y que, por tanto, corresponde a otra tipología arquitectónica. Años más tarde ese inmueble fue reformado y transformado, al convertir las diferentes plantas en pisos, de manera que el antiguo vestíbulo de la residencia actúa a modo de portal. No obstante, nos referimos a esta obra, promovida por Fernando Merino, más adelante. ornamentación fue clave en estos inmuebles y en muchos casos enfatizó la composición de las fachadas. Además, los adornos delataban exteriormente la importancia de las viviendas, dado que se concentraban en los frentes de los primeros pisos en detrimento de los restantes de rentas más económicas. Un planteamiento similar prevaleció en las zonas comunitarias de los inmuebles, de manera que se prestó más atención a la puerta principal que a la que separaba el portal de la caja de la escalera.

Así las cosas, la decoración fue un símbolo de estatus, algo evidente también en el interior de las viviendas y en los propios portales, a los que la mayoría de los arquitectos dedicaron atención desde el punto de vista estético y funcional ${ }^{5}$. En esta dirección la contratación de Zuloaga en los ejemplos que abordamos es de por sí explícita, dada la resistencia de la cerámica y su fácil limpieza, aparte de sus posibilidades ornamentales y simbólicas, máxime cuando se contaba con un artista tan prestigioso, cuyos honorarios eran importantes. A su vez lo último pone de manifiesto la capacidad económica de los promotores y su interés por dotar de zaguanes singulares a los inmuebles en cuestión.

LOS PORTALES DE LAS CASAS DE VECINDAD DE NICOLÁS MURGA Y ARMANDO OTERO EN BILBAO

El primer portal que diseñó Daniel Zuloaga en Bilbao fue el de la casa de Nicolás Murga Íñiguez ${ }^{6}$, ubicada en la calle Gardo-

\footnotetext{
${ }^{5}$ Vid. un análisis de los planteamientos dominantes en estos espacios en lo tocante al caso de Bilbao en Maite Paliza Monduate, "La búsqueda de representatividad y distinción en los espacios comunitarios de las casas de vecindad: portales y escaleras de Bilbao 1880-1910", en Congreso Internacional Imagen y apariencia, coord. por Concepción de la Peña Velasco y Manuel Pérez Sánchez (Murcia: Universidad de Murcia, 2009), s.p.

${ }^{6}$ Nicolás Murga, nacido en Burgos en 1857, se instaló en Bilbao a comienzos de los años setenta del siglo XIX. Ejerció como procurador de los tribunales en el municipio vizcaíno de Balmaseda y tuvo intereses en la industria minera. En este sentido, dirigió la Sociedad
} 
qui número $11^{7}$. Este zaguán, realizado durante la segunda etapa de su carrera, resulta, hoy por hoy, el mejor en su género dentro de la producción del ceramista. Sin embargo, hasta hace poco tiempo en la bibliografía específica sobre el artista constaba como obra no localizada y apenas había referencias al respecto, más allá de algunos documentos incorporados en la tesis doctoral de María Jesús Quesada ${ }^{8}$. El propio ceramista quedó muy satisfecho del resultado, hasta el extremo de que poco después ilustró la portada de un catálogo comercial de sus productos con uno de los bocetos preparatorios para este vestíbulo ${ }^{9}$ (Fig. 1). En este caso la decoración se materializó entre 1901 y 1902, período en el que el artífice diseñó paneles para los zaguanes de dos casas de vecindad madrileñas a petición del arquitecto Jesús Carrasco-Muñoz Encina (1869-1957, titulado en

Española de Explotaciones Mineras, compañía que instaló en los bajos del inmueble que nos ocupa unas oficinas y un laboratorio, y que, entre otras cosas, explotó parte del coto El Hoyo - Ontón, sito en Cantabria. Además hizo incursiones en la industria del ferrocarril, en concreto en la Constructora de Zalla a Solares (1893), de la que fueron socios Víctor Chávarri Salazar y sus hermanos Segundo y Félix Murga, con los que también creó la sociedad Murga Hermanos, establecida igualmente en el edificio que analizamos en estas líneas. Aquella línea férrea, en la que invirtieron muchos propietarios de la comarca de Las Encartaciones, estaba destinada a hacer confluir los ferrocarriles del Cadagua y Santander y de ese modo conseguir una mayor rentabilidad de los mismos y de los negocios mineros de los inversores. A partir de 1895, la sociedad pasó a denominarse Compañía Constructora del Ferrocarril de Zalla a Solares. Estas noticias proceden de Archivo de la Diputación Foral de Bizkaia (ADFB), Sección Municipal, Bilbao, leg. 5/119/4; Pedro Fernández Díaz-Sarabia, El ferrocarril hullero de La Robla a Valmaseda 1890-1972 (Salamanca: Junta de Castilla y León, 2003).

7 ADFB, Sección Municipal, Bilbao, leg. 5/119/4. Sobre este inmueble vid. un comentario en Elías Mas, "Casa en Cardenal Gardoqui esquina con Bertendona", Bilbao, no Julio (2009), 9.

\footnotetext{
${ }^{8}$ Quesada Martín, “Daniel Zuloaga. Ceramista y pintor...", T. I, 285.

9 Cerámica artística para construcciones. Segovia (Madrid, sin editor, 1904), s.p.
}

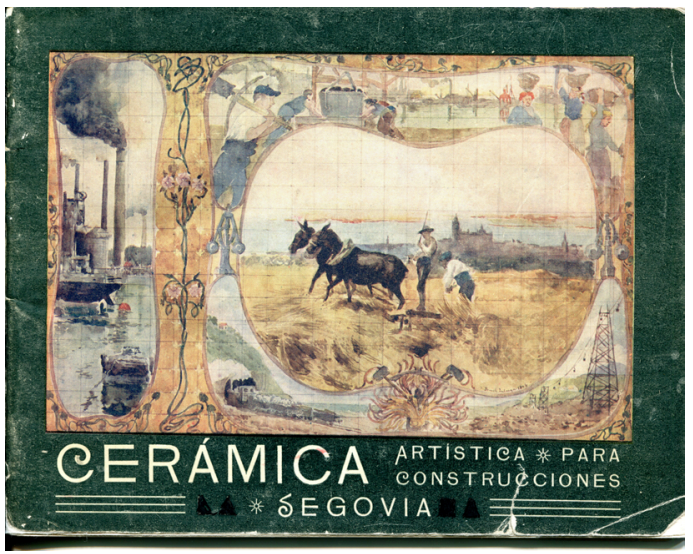

- Fig. 1. Daniel Zuloaga. Portada de catálogo comercial de sus productos. 1904. Archivo Daniel Zuloaga Segovia-Junta de Castilla y León.

$1894)^{10}$. No obstante, en este ejemplo bilbaíno, como veremos más adelante, la cerámica ganó claramente protagonismo, aproximándose al planteamiento desplegado por el artista en los recibidores de viviendas unifamiliares, donde los frisos tendieron a cubrir por completo las paredes.

La casa de Nicolás Murga es un inmueble que inicialmente constaba de semisótano, planta baja, cuatro pisos y desván bajo cubierta. Estilísticamente se enmarca dentro de las recetas de corte ecléctico al uso a finales del siglo XIX, bien es cierto que la combinación en los paramentos de sillería, piedra artificial y estuco rojizo enlaza con la llamada arquitectura polícroma. Se trata de una corriente que alcanzó gran difusión y que incentivó la aplicación de frisos cerámicos en el exterior y el interior de los edificios, faceta en la que en nuestro país destacó sobremanera Zuloaga.

Respecto a la arquitectura polícroma y la decoración cerámica de este portal, que en definitiva responde a la misma corriente, hay que tener en cuenta que el edificio fue diseñado en junio de 1899 por Luis Aladrén Mendívil (1852-1902, titulado en 1881), introductor en el País Vasco de la cerámica

\footnotetext{
${ }^{10}$ Se trata de las casas de la Marquesa de Eguarás (1899), situada entre las calles Barquillo y Prim, y Luisa de la Hoz (1900), ubicada en la plaza de Chamberí, a las que hacemos referencia más adelante.
} 
aplicada a la arquitectura. Natural de Zaragoza, empleó por primera vez ese tipo de revestimientos en 1882 en el Casino de San Sebastián -hoy, casa consistorial-, diseñado en colaboración con Adolfo Morales de los Ríos (1858-1928, titulado en 1882). Un año después instaló su residencia en la capital guipuzcoana donde habían nacido sus abuelos maternos ${ }^{11}$.

La contratación de Aladrén fue consecuencia de relaciones de estrecha amistad. En este sentido hay que señalar que Murga estaba casado con Basilia Chapartegui, natural de Zumaya (Guipúzcoa), donde en un inmueble proyectado por el primero residía su familia. El propio tracista también tenía casa de descanso en esa localidad, decorada con piezas de cerámica diseñadas por Zuloaga $^{12}$. Con anterioridad la inclinación

\footnotetext{
11 Tras concluir sus estudios viajó por diversos
} países de Europa y durante algún tiempo residió en París. Su producción se enmarca dentro del eclecticismo, mostrando una gran inclinación hacia la llamada arquitectura polícroma, mientras que en sus obras religiosas prevalece el neomedievalismo. Muchos de sus proyectos fueron diseñados conjuntamente con Adolfo Morales de los Ríos. Su obra se encuentra repartida entre Zaragoza, San Sebastián y Bilbao. Entre sus principales proyectos, aparte del Casino de San Sebastián, sobresalen la Joyería Aladrén (1885) de Zaragoza, hoy transformada en café, el Convento de las Siervas de María (1886) de San Sebastián y el citado Palacio de la Diputación de Vizcaya. Con respecto a Aladrén vid. María del Carmen Rodríguez Sorondo, Arquitectura pública en la ciudad de San Sebastián (18131922) (San Sebastián: Sociedad Guipuzcoana de Ediciones y Publicaciones, 1985); Yasmina Grandio, Urbanismo y arquitectura ecléctica en San Sebastián. 1890-1910 (San Sebastián: Sociedad Guipuzcoana de Ediciones y Publicaciones, 1987); Clotilde Olaran, Palacio de la Diputación Foral de Bizkaia (Bilbao: Diputación Foral de Bizkaia, 1991).

12 Así consta en una carta, dirigida por Aladrén a Zuloaga el 3 de junio de 1898, en la que le pidió un medallón de cerámica de 0’96 m de diámetro con las letras VP, que correspondían a las iniciales del nombre de la casa "Villa Pilarchu". Quesada Martín, "Daniel Zuloaga. Ceramista y pintor...", T. II, 107. Esta misiva incluye un croquis del tondo dibujado por el arquitecto. Archivo de Daniel Zuloaga en Segovia (ADZS), leg. 1, Correspondencia 1850-1899. de aquel hacia la arquitectura polícroma le había llevado a establecer vínculos con el ceramista, primero profesionales y más tarde de amistad.

No obstante, Aladrén nunca llegó a residir de forma continuada en Bilbao, de manera que un colaborador suyo, el arquitecto francés Jean Baptiste Darroqui ${ }^{13}$, fue quien se

\footnotetext{
${ }^{13}$ Nacido en Saint Jean de Luz (Francia) en 1859, se afincó en Bilbao en los últimos meses de 1891 o en los primeros de 1892. Para entonces ya estaba casado con su compatriota Louise Etcheberri y tenía un hijo, posteriormente la pareja tuvo otros vástagos que vieron la luz en Bilbao, incluido Maurice (1900-1965), que con el tiempo también sería arquitecto. Sobre su curiosa situación profesional y los problemas impuestos por la legislación que le impedían firmar obras como arquitecto, dada su condición de extranjero, es explícito que en 1895, con motivo de la elaboración del padrón
} municipal, se registró como delineante.

Desconocemos los motivos que le llevaron a continuar en Bilbao, una vez inaugurado el Palacio de la Diputación y fallecido Aladrén, pero es probable que la gran actividad constructiva que atravesaba la ciudad y sus contactos fueran determinantes. Así en los primeros años del siglo XX ideó obras importantes, siendo el artífice de los mejores ejemplos del Art Nouveau. Por un lado, acometió la conclusión de la casa de vecindad de Pedro Montero entre las calles Alameda Recalde y Colón de Larreátegui, encargada a Aladrén en 1901. La comparación entre el alzado inicial y el resultado final resulta muy llamativa, dadas sus profundas diferencias, decantándose el francés por el modernismo, a diferencia de la propuesta más clásica del primero. También fue el autor del Teatro Campos Elíseos, inaugurado en 1902, al que aludimos más adelante. Precisamente los Chávarri, industriales que salen a colación en este artículo, tuvieron relación, aunque fuera indirecta, con estos edificios, pues Vivancos, uno de los promotores del teatro, tenía nexos laborales con Víctor Chávarri y consta la vinculación de Montero con esta familia, que acabó siendo propietaria de la referida casa de vecindad. Además fue el artífice del desaparecido Palacio de Manuel Chávarri (1903) en Portugalete (Vizcaya), que tenía algún detalle Art Nouveau. Otras obras de Darroqui en Vizcaya fueron los chalés de las familias Hernáiz y Portillo en Carranza. Con respecto a este técnico vid. Geneviève Mesuret y Maurice Culot, Architectures de Biarritz et de la Côte basque de la Belle Epoque aux années trent (Liège: Mardaga, 1990); Maite Paliza Monduate, "Limitations Stemming from the Legal Regulation of Designs of Foreign Architects in Spain in the 19th Century. The Case of the Basque 
afincó en esta ciudad en la década de los noventa para estar al frente de los trabajos del Palacio de la Diputación, la primera obra del aragonés en la capital vizcaína. Lo mismo ocurrió con la casa de vecindad de Murga, tal como corrobora la documentación hallada en el archivo de Daniel Zuloaga. Asimismo Severino de Achúcarro Mocoroa (18411910, titulado en 1866$)^{14}$ figuró como responsable de la dirección de la construcción del inmueble tras el repentino fallecimiento del tracista en enero de 1902, cuando el edificio estaba prácticamente terminado, cosa de lo que también queda constancia en el referido fondo documental. La normativa vigente en España prohibía que los técnicos extranjeros asumieran tareas de ese tipo, algo que imposibilitaba que Darroqui apareciera oficialmente al frente de la construcción.

De todos modos, lo relativo al portal estaba ya muy definido en diciembre de 1901 y la documentación corrobora que Aladrén se ocupó personalmente del mismo. Tras su óbito fueron Zuloaga y Murga los que tomaron las últimas decisiones al respecto.

Country", en Nuts \& Bolts of Construction History Culture, Technology and Society, ed. por Robert Carvais, André Guillerme, Valérie Nègre y Joël Sakarovitch (París: Picard, 2012), T. I, 527-553.

\footnotetext{
${ }^{14}$ Achúcarro fue una figura capital en la arquitectura bilbaína de la segunda mitad del siglo XIX y la primera década del XX. Diseñó en colaboración con los ingenieros Alzola y Hoffmeyer el Proyecto de Ensanche de la ciudad en 1876. Fue un arquitecto prolífico que estilísticamente se enmarca dentro del eclecticismo, aparte de diseñar numerosas restauraciones, sobre todo de inmuebles religiosos, acorde a los postulados violletianos. Tuvo además un gran protagonismo en la vida cultural de la capital vizcaína. Entre sus proyectos más destacados cabe señalar el Cementerio de Portugalete (Vizcaya) (1873), la sede de la Sociedad El Sitio (1888) en Bilbao, la Portada y Torre de la Basílica de Santiago (1881-1891) en Bilbao, el Hospital Psiquiátrico (1892) de Bermeo (Vizcaya), el Casino (1894) de esta última localidad, la primitiva iglesia de las Mercedes (1888) de Las Arenas en Guecho (Vizcaya) (derribada) y la Escuela de Ingenieros Industriales de Bilbao (1900). Con respecto a la obra de este arquitecto, aparecen referencias breves en numerosas publicaciones, pero a día de hoy no contamos con una monografía específica.
}

Aparte de la inclinación del zaragozano hacia los revestimientos cerámicos, la decoración del zaguán se enmarca en un contexto de estrechas relaciones entre los tres arquitectos implicados en el proyecto y Zuloaga, ya que por las mismas fechas Darroqui y Achúcarro le encargaron otras obras ${ }^{15}$. Con independencia de la concurrencia de estos tres técnicos, son igualmente relevantes para el caso los vínculos entre las familias Allende, Murga y Chávarri ${ }^{16}$, que por entonces coincidieron en diversas actividades empresariales, dándose la circunstancia de que en muchos de los proyectos arquitectónicos que promovieron también intervinieron los referidos facultativos.

El portal de la casa de Nicolás Murga tiene planta rectangular y está articulado en dos niveles, el inferior mucho más amplio que el superior. Ambos están enlazados por una escalera, dispuesta en el eje central. El acceso lo constituye un hueco adintelado con una puerta de madera de doble hoja. Una mampara de madera y cristal, dotada de cuerpos fijos en los extremos y puertas en

15 Consta que por entonces Achúcarro le hizo encargos para las casas de Tomás y Plácido Allende, Sr. Govillar, Sr. Achútegui y la Estación de Ferrocarril de la Compañía Santander-Bilbao en esta última localidad, aparte de lo dicho sobre la casa de Tomás Allende, mientras que Darroqui hizo lo propio para el Teatro Campos y la casa de Martínez Rodas en Las Arenas. Por último, Aladrén le solicitó murales para la Diputación de Vizcaya, la casa de Segundo Murga en Bilbao y el inmueble que nos ocupa. Así figura en "Cerámica artística para construcciones. D. Daniel Zuloaga. Segovia", en Talleres de hijos de Daniel Zuloaga - Segovia, 25 (Madrid: sin editor, sin fecha), s.p.

${ }^{16}$ Las relaciones empresariales entre estos clanes fueron muy estrechas, tal como reflejan numerosas investigaciones. En esta dirección vid., entre otros, Manuel González Portilla, La siderurgia vasca (18801901). Nuevas tecnologías, empresarios y política económica (Bilbao: Universidad del País Vasco, 1985); Manuel Montero, Mineros, banqueros y navieros (Bilbao: Beitia, 1990) y La California del hierro: las minas y la modernización económica y social de Vizcaya (Bilbao: Beitia, 1995); Fernández, El ferrocarril hullero...; Eduardo José Alonso Olea, Víctor Chávarri (1894-1900). Una biografía (San Sebastián: Eusko Ikaskuntza, 2005). 
el medio, separa el zaguán de la caja de la escalera que comunica verticalmente el edificio. Por otra parte, el solado es de mármol rosáceo de Ereño, material muy extendido en los zaguanes bilbaínos de la época, mientras que el techo está resuelto a modo de un falso artesonado de escayola, pintado en tonos marrones, pardos y blancos con algún toque dorado, simulando madera. Se trata de una solución relativamente frecuente en esos vestíbulos, donde, no obstante, predominaron los techos lisos enmarcados por cornisas y ménsulas del referido material. Las paredes están divididas en dos partes, la inferior a modo de zócalo, resuelto mediante una composición de madera y mármol del mismo tipo que el del suelo, cosa que ahonda en la policromía. Este friso alcanza 1'56 m de altura dentro de las medidas que fueron usuales hacia 1900, pues ulteriormente tendieron a ser más elevados. La franja superior está cubierta por completo por los murales cerámicos que nos ocupan, cuya superficie total, según apreciación del propio Zuloaga, asciende a 28 metros cuadrados ${ }^{17}$.

En un principio Aladrén contempló pilastras adosadas a las paredes que finalmente no se materializaron, porque interferían con los forros de cerámica. Así se desprende de una carta dirigida por Murga al artista el 3 de diciembre de 1901, en la que le preguntaba sobre pormenores de los murales. En esa misiva también le sondeaba sobre la posibilidad de colocar o no "las columnas", previstas inicialmente por el tracista para delimitar las dos partes del vestíbulo, pues, según le había comentado Darroqui, ocultarían parte de la decoración cerámica ${ }^{18}$. Ese tipo de soportes fueron habituales en los

${ }^{17}$ Quesada Martín, “Daniel Zuloaga. Ceramista y pintor...", T. I, 232 y T. II, 178.

18 Quesada Martín, “Daniel Zuloaga. Ceramista y pintor...", T. II, 177. ADZS, leg. 2, Correspondencia 1900-1901, Carta de Nicolás Murga a Zuloaga, fechada el 3 de diciembre de 1901. En esta misiva el promotor utilizó el término columna por falta de precisión, pero no tenemos duda de que se trataba de pilastras, de acuerdo a lo usual en el diseño de los portales en aquellos años. portales de la época para marcar la separación entre los distintos tramos de los zaguanes. También fueron barajados en este inmueble, pero finalmente fueron descartados. A lo largo del último mes de 1901 quedaron perfilados todos los detalles del vestíbulo, el ceramista recibió indicaciones sobre la altura de las paredes, que no era la misma en toda la estancia ${ }^{19}$, y la anchura de los muros que flanquean la puerta principal $^{20}$.

Zuloaga articuló el mural de manera que en los lados largos del portal se suceden dos composiciones de diferente tamaño y anchura, pues cada una corresponde a uno de los dos tramos en que está dividido el vestíbulo. Un tallo con decoración de látigo, del que nacen vástagos vegetales y flores, en torno al cual revolotean varias mariposas, separa estas escenas que a su vez están enmarcadas por molduras sinuosas de las que brotan tallos curvilíneos. Por otra parte, cada una de las paredes que flanquea la entrada principal cuenta con otro panel con el mismo tipo de marco. Así las cosas, el programa estaba compuesto por seis cuadros principales, de los que dos están enmarcados por plafones secundarios.

La temática fue impuesta en parte por el comitente, que propuso asuntos alusivos a actividades de la economía vizcaína: la industria, la minería, la pesca y la agricultura. Así lo corrobora la memoria familiar ${ }^{21}$, aunque son cuestiones recurrentes en la obra de Zuloaga y, como veremos, finalmente el programa también incorporó referencias segovianas.

En febrero de 1901 el artista tenía preparados los bocetos de cuatro plafones para los que creemos partió de fotografías, pues con frecuencia utilizó imágenes de ese tipo

${ }^{19}$ ADZS, Carpeta sin clasificar relativa a diversas obras, incluida la casa de Nicolás Murga.

${ }^{20}$ ADZS, leg. 2, Correspondencia 1900-1901, Cartas de Nicolás Murga a Zuloaga, fechadas el 11 y el 14 de diciembre de 1901.

${ }^{21}$ Testimonio del arquitecto Javier Gracia Basterra, bisnieto del promotor del inmueble. 
para sus composiciones, pese a que en nuestra investigación no hayamos conseguido localizar todas las que debió manejar en este ejemplo concreto. A menudo usó fotografías tomadas por él mismo, así como otras pertenecientes a reputados artistas de esa disciplina ${ }^{22}$. Los paneles en cuestión correspondían a los dos que delimitaban la entrada al edificio y los dos destinados a decorar cada uno de los flancos del primer tramo del portal. Así consta en una carta que el artífice envió desde Gijón (Asturias) a su ayudante Gregorio Arnanz ${ }^{23}$. Por entonces también suministró azulejos seriados para alicatar dependencias de las viviendas del mismo inmueble.

Los murales dispuestos junto al acceso miden $0^{\prime} 80 \mathrm{~m}$ de anchura y están presididos por una figura masculina ataviada con indumentaria popular. Uno de ellos corresponde a un aldeano vasco y el otro a un labriego segoviano. El primero, denominado por el propio Zuloaga "bueyero bascongado" 24 , dirige con su vara una pareja de bueyes, teniendo como telón unas estilizadas colinas en las que domina la gama verdosa. Va tocado con la típica boina $\mathrm{y}$, aunque fue ejecutado con un marcado abocetamiento con pintura sobre esmalte, se percibe claramente que calza las típicas albarcas, aparte de llevar pantalón azul de tela de mahón, un fajín atado a la cintura, camisa blanca de mangas abullonadas abotonada hasta el cuello, chaleco y el denominado "elástico", una chaqueta de

${ }_{22}$ En el archivo del ceramista se conserva una colección ingente de fotografías que desafortunadamente están sin catalogar debidamente, aunque durante nuestra investigación hemos revisado todo el material disponible a día de hoy. Sobre la relación de Daniel Zuloaga con la fotografía vid. Quesada Martín, Daniel Zuloaga 1852..., 50. Rubio Celada, Los Zuloaga..., 159165.

${ }^{23}$ ADZS, leg. 2, Correspondencia 1900-1901, Carta de Zuloaga a Gregorio Arnanz fechada el 8 de febrero de 1901.

${ }^{24}$ ADZS, leg. 2, Correspondencia 1900-1901, Carta de Zuloaga a Gregorio Arnanz, fechada el 8 de febrero de 1901. punto, igualmente de tono azulado, colgada del hombro izquierdo ${ }^{25}$.

El otro fue realizado de una forma más minuciosa, lo que se traduce en una representación más detallada del traje, aunque sin la precisión necesaria para reflejar meticulosamente la filigrana de los bordados o picaos característicos de esa indumentaria tradicionall $^{26}$. Lleva montera sobre la cabeza y viste calzón de paño oscuro que se extiende hasta debajo de la rodilla, chaquetilla del mismo tono y un chaleco marrón. Calza botas y polainas, así como medias azules que llegan hasta el encuentro del pantalón. Completa su atuendo con la habitual capa oscura colocada también sobre el hombro izquierdo. Detrás de él se vislumbra un fondo arquitectónico un tanto desdibujado en el que se divisa la silueta, igualmente simplificada, de la torre de la Catedral de Segovia y las construcciones de su entorno. La pose y la disposición del protagonista, colocado muy en primer término, inducen a la conclusión de que posó ex profeso para el artífice, seguramente para una de las muchas fotografías de tipos segovianos que reunió a lo largo de su vida.

Los cuadros grandes, destinados a realzar los lados largos del portal, constituyen una representación de la minería y la agricultura. El primero mide 2'76 m de ancho y está protagonizado por el cargadero de mineral de El Piquillo, sito entre la ensenada de Ontón y la rada del Berrón en Castro Urdiales (Cantabria), encargado por Chávarri y Cia., empresa propietaria de varias minas en la zona, al arquitecto e ingeniero Alberto Palacio Elissague (1856-1939, titulado en

${ }^{25}$ Sobre los detalles de la indumentaria popular vasca vid. Karmele Goñi, Evolución del traje vizcaíno (Bilbao: Caja de Ahorros Vizcaína, 1982).

${ }^{26}$ Con respecto a este punto vid. Ángela López García-Bermejo, El traje popular segoviano (Segovia: Caja de Ahorros y Monte de Piedad de Segovia, 1985); Esther Maganto, "Los picaos en la indumentaria tradicional segoviana. Tipología, simbología y particularismos", en La palabra vestida. Indumentaria histórica y popular (Soria: Diputación Provincial, 2015), 193-221. 


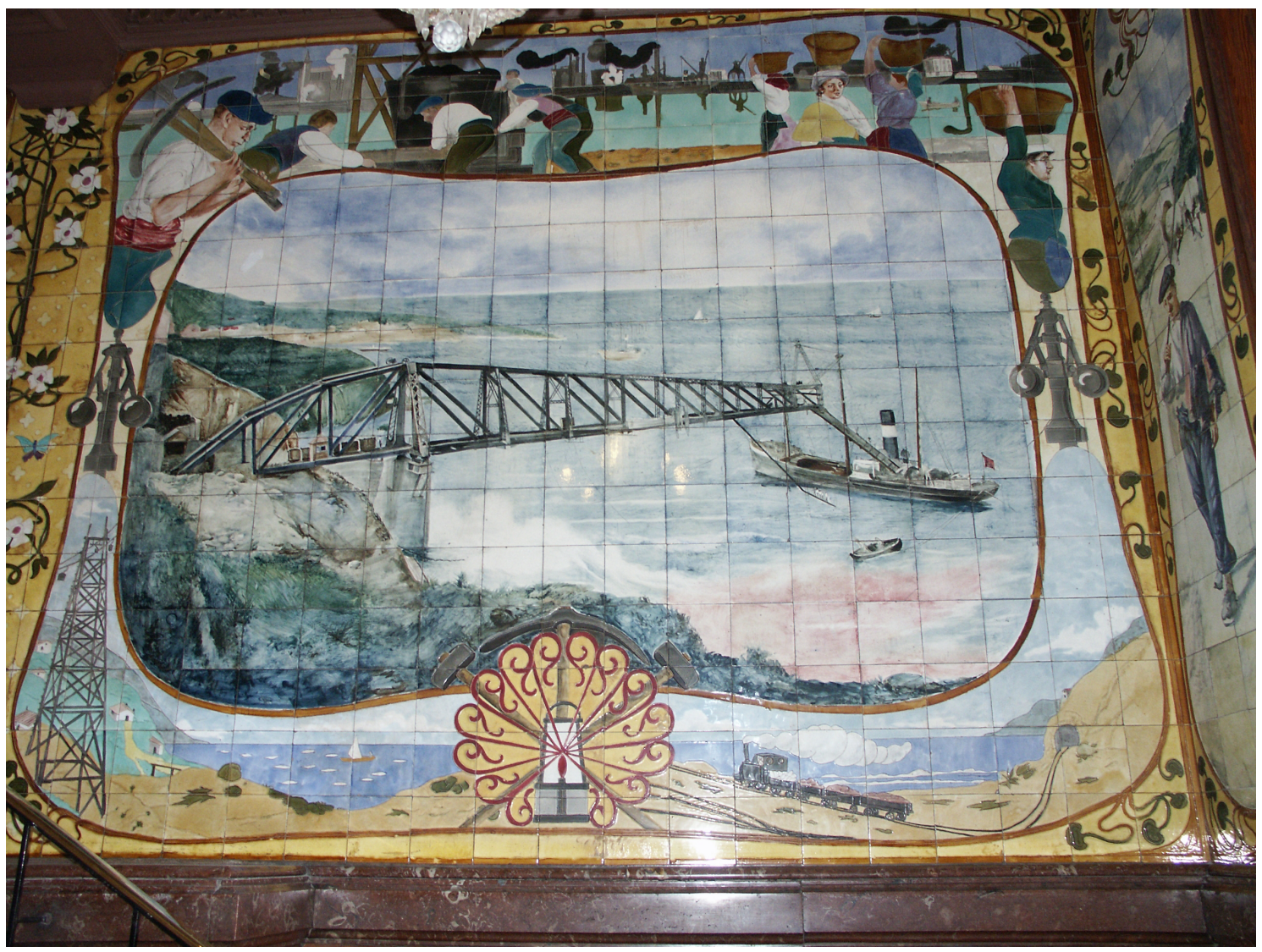

- Fig. 2. Daniel Zuloaga. Panel del Cargadero del Piquillo en el portal de la casa de Nicolás Murga, calle Gardoqui nº 11 (Bilbao). 1902. Foto de la autora.

1882), autor del Puente Vizcaya, inaugurado en 1893, para unir las dos márgenes de la ría del Nervión entre las localidades vizcaínas de Guecho y Portugalete. Aquella infraestructura en desuso desde hace tiempo, pero de la que aún subsisten restos, estaba también vinculada a Nicolás Murga, puesto que era director de la Sociedad Española de Explotaciones Mineras, firma que también poseía allí yacimientos. Además se da la circunstancia de que esta compañía instaló en los bajos de la casa de vecindad que nos ocupa unas oficinas y un laboratorio ${ }^{27}$. En el mural, dominado por una rica gama de azules $\mathrm{y}$ verdes, se identifica perfectamente el paraje y el cargadero, en cuya desembocadura el

27 En julio de 1901, Murga pidió permiso al Ayuntamiento de Bilbao para empezar a utilizar toda la planta baja del inmueble como sede de las referidas oficinas, ya que ese piso estaba terminado. El consistorio dio el placet ese mismo mes. ADFB, Sección Municipal, Bilbao, leg. 5/119/4. ceramista dispuso un vapor preparado para transportar la mercancía. En nuestra opinión Zuloaga partió inequívocamente de una fotografía, que seguramente le suministró el propio Murga (Fig. 2).

El panel de la pared contraria mide 2'80 $\mathrm{m}$ de ancho. Aquí predominan los tonos blanquecinos y pardos y alude a la agricultura mediante un campo de cereal con tres labriegos realizando trabajos de siega y recogida de la mies. Aparecen junto a un carro, cargado con haces y tirado por mulas, mientras que diversos aperos propios de la labranza y un botijo ocupan el primer plano. Este tema de claras implicaciones castellanas tuvo que ser una concesión a Zuloaga, ya que nada tenía que ver con el promotor $y$, por el contrario, constituye un lugar común en la producción regionalista del artífice. Es una escena tópica y con menos fuerza que la anterior, algo de lo que fue consciente el propio autor, quien en una carta dirigida a uno 
de sus colaboradores le preguntó si desmerecía mucho respecto al plafón, denominado por él mismo como "la grúa"28 (Fig. 3).

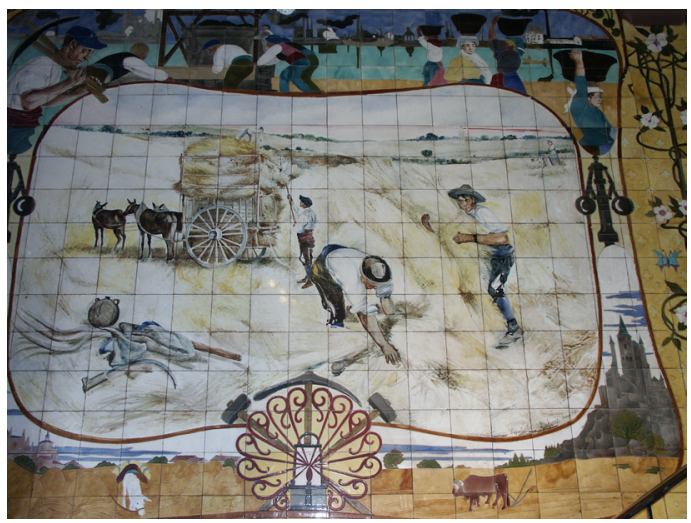

- Fig. 3. Daniel Zuloaga. Panel con labriegos segovianos en el portal de la casa de Nicolás Murga, calle Gardoqui no 11 (Bilbao). 1902. Foto de la autora.

En buena medida los murales de los tipos populares completan o están claramente relacionados con la escena grande de la pared contigua, de manera que el primer tramo del portal está dividido longitudinalmente en dos unidades temáticas, una vinculada a motivos vascos y la otra a asuntos segovianos, algo que ya resaltó la prensa de la época ${ }^{29}$. Este planteamiento podría explicar que estos fueran los cuatro primeros bocetos pergeñados por Zuloaga.

No obstante, las dos composiciones grandes están rodeadas por una orla, que en la parte superior ahonda en el mundo de la minería. Esta banda, cuyo perímetro también está aderezado con sinuosos vástagos vegetales de impronta modernista, incluye unas mujeres, representadas de busto o de tres cuartos, portando cestos sobre sus cabezas. En principio podría tratarse de las típicas sardineras y la única referencia a la pesca de todo el mural. Sin embargo, unidas a temas mineros o fabriles, como es el caso,

${ }^{28}$ ADZS, leg. 2, Correspondencia 1900-1901, Carta de Zuloaga a Gregorio Arnanz, fechada el 8 de febrero de 1901.

${ }^{29}$ M. E., "Una obra de arte", El Liberal (Bilbao), 16 de abril de 1902.

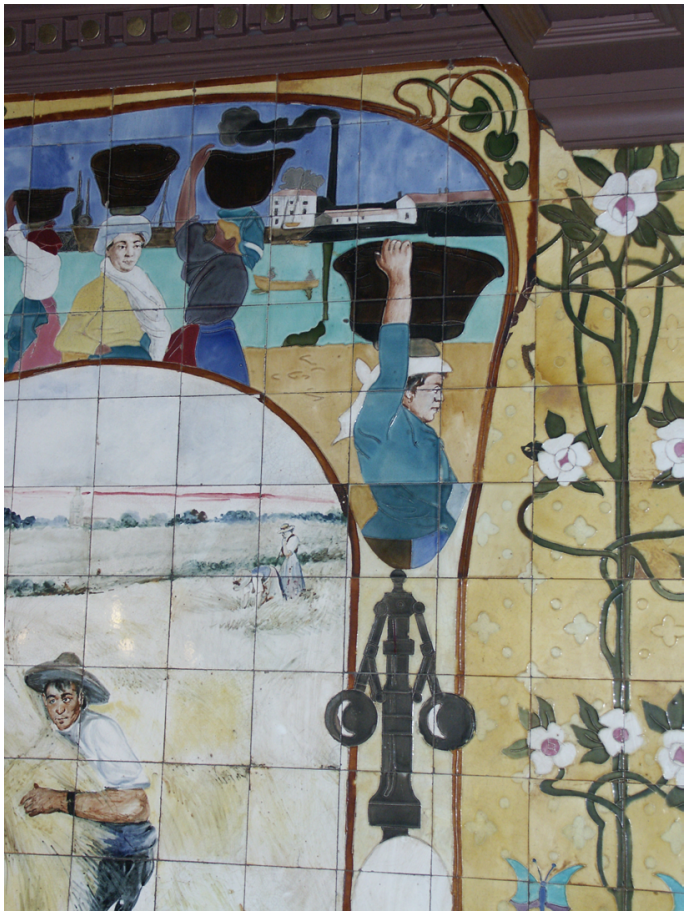

- Fig. 4. Daniel Zuloaga. Detalle del panel que enmarca el plafón de la escena de los labriegos segovianos en el portal de la casa de Nicolás Murga, calle Gardoqui no 11 (Bilbao). 1902. Foto de la autora.

estas figuras han sido identificadas como cargadoras de mineral ${ }^{30}$, interpretación que damos por buena en este ejemplo (Fig. 4). Están acompañadas por unos operarios, que faenan con un balde aéreo para transporte de mercancía, y un picador que porta al hombro su herramienta de trabajo. Toda la composición se recorta sobre un horizonte de tipo industrial, repleto de humeantes chimeneas, que corresponde al perfil de Sestao (Vizcaya) a principios del siglo XX. Para la identificación del paraje resulta reveladora la silueta de una construcción blanquecina que destaca entre el resto de estructuras fabriles junto al grupo que maniobra con el citado balde. Se trata de la desaparecida Iglesia de El Carmen de esa localidad, templo neomedievalista, diseñado por el arquitecto José María Basterra Madariaga en 1897. Este edificio fue sufragado por el industrial José María Martínez de las Rivas, propietario de la fábrica San Francisco de la localidad.

\footnotetext{
${ }^{30}$ Rubio Celada, Los Zuloaga. Artistas..., 172.
} 
Se da la circunstancia de que fue inaugurado en julio de 1899, es decir poco antes de la visita del ceramista ${ }^{31}$. Las construcciones anejas pertenecerían a la antigua fábrica $L a$ Vizcaya, fundada en 1882 por un grupo de empresarios, entre los que figuraban varios miembros de la familia Chávarri. El proyecto de este complejo industrial, dotado de tres altos hornos, fue realizado por la firma belga Cockerill y su construcción concluyó en 1884 $4^{32}$ (Fig. 5).

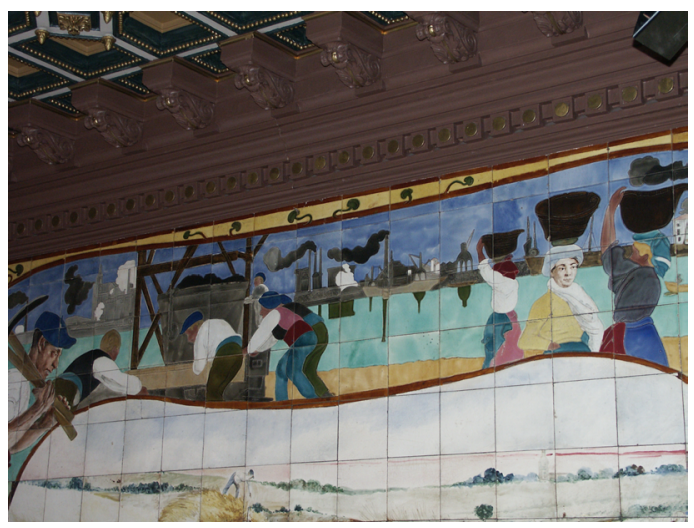

- Fig. 5. Daniel Zuloaga. Plafón que remata el mural de la escena de los labriegos segovianos en el portal de la casa de Nicolás Murga, calle Gardoqui no 11 (Bilbao). 1902. Foto de la autora.

Los detalles de la banda inferior son diferentes, puesto que en el panel del cargadero de El Piquillo vemos un ferrocarril minero con los correspondientes vagones llenos de mercancía, un caserío en medio de un prado verde, así como un trozo de mar y un tranvía aéreo, todo ello característico de la geografía de la zona minera vizcaína. Por el contrario, en el plafón segoviano se aprecia un campo amarillento, propio de la Meseta castellana, con una pareja de bueyes que tiran de un

31 Gorka Pérez de la Peña Oleaga, Arquitectura religiosa contemporánea en Bizkaia 1865-1975. Del Romanticismo al Movimiento Moderno (Bilbao: Obispado de Bilbao. 2004), 64 y 70; Cipriano Ramos Larriba, Monografías de Pueblos de Bizkaia. Sestao (Bilbao: Diputación Foral de Bizkaia, 1997), 286.

32 Manuel González Portilla, La siderurgia vasca (1880-1901) Nuevas tecnologías, empresarios y política económica (Bilbao: Universidad del País Vasco, 1985), 41-60. arado y un burro que porta unas alforjas, así como el Alcázar y la Catedral de Segovia, en la que se percibe claramente el exterior de la Capilla del Sacramento, edificios estos últimos concebidos en muchos casos por Zuloaga como auténticos símbolos de esa ciudad ${ }^{33}$. No obstante, en el centro de la franja figura en los dos plafones el mismo motivo, compuesto a base de líneas serpenteantes y herramientas propias de la minería.

Bastantes meses después, en octubre de 1901, el ceramista realizó los bocetos de los últimos murales, destinados al segundo tramo del portal, que miden 0 ' $87 \mathrm{~m}$ de ancho, y muy probablemente el del aludido friso de tema minero e industrial que remata los cuadros de El Piquillo y los campesinos segovianos. Sabemos que para ello se trasladó personalmente a "Somorrostro", según consta en una carta dirigida a su socio Vargas $^{34}$. Hay que aclarar que en esta misiva $\mathrm{Zu}-$ loaga no se refería a la zona vizcaína conocida hoy día con ese nombre, sino al antiguo valle homónimo integrado por entonces en la comarca de Las Encartaciones, que englobaba, entre otros, los actuales municipios de Sestao y Santurce. Decimos esto porque en el panel contiguo a la escena segoviana se identifica al fondo el monte Serantes, sobre el que se recortan varias chimeneas y construcciones de la mentada fábrica La Vizcaya. En primer término advertimos unas pilas de carbón, a juzgar por su color negruzco, justo en el punto donde el río Galindo desemboca en la ría del Nervión. Completan la escena unas embarcaciones que inequívocamente revelan el gusto por la anécdota del artífice. Este tipo de asuntos fueron frecuentes a principios del siglo XX en la obra de Zuloaga tanto en las piezas de arte mueble como en los revestimientos destinados a la arquitectura.

${ }^{33}$ Rubio Celada, Los Zuloaga. Artistas..., 139.

${ }^{34}$ ADZS, leg. 2, Correspondencia 1900-1901, Carta de Zuloaga a Vargas, fechada el 26 de octubre de 1901, en la que comenta que iría "mañana a Somorrostro a pintar dos vistas para unos paños del portal de Murga". 


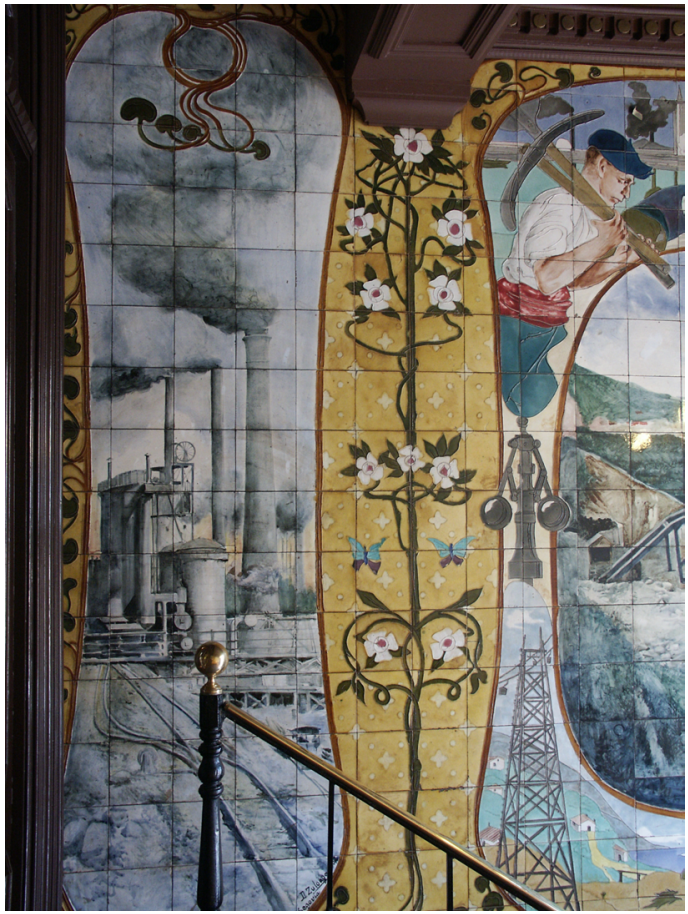

- Fig. 6. Daniel Zuloaga. Plafones del alto horno y subiente modernista en el portal de la casa de Nicolás Murga, calle Gardoqui no 11 (Bilbao). 1902. Foto de la autora.

La composición contraria, contigua al plafón del cargadero de El Piquillo, también está presidida por instalaciones fabriles y resuelta con la misma gama grisácea rica en matices. Se puede afirmar que son variaciones sobre el mismo tema y una evocación del progreso y la industria. En este caso el motivo principal es un alto horno, rodeado por chimeneas y precedido por el cuerpo cilíndrico de una estufa para calentar el aire. Aquí también advertimos el característico interés por el detalle de Zuloaga, pues se recreó con cierto detenimiento en las poleas de activación del montacargas, mientras que el primer término está surcado por un intricado trazado de red ferroviaria que aseguraba la recepción del suministro a pie de horno. Suponemos que es un rincón de la citada fábrica, aunque, a diferencia del mural anterior, carecemos de referencias concretas que garanticen una identificación exacta (Fig. 6).

Poco después de su desplazamiento a este paraje vizcaíno, Zuloaga debió realizar el boceto que más tarde utilizó para ilustrar

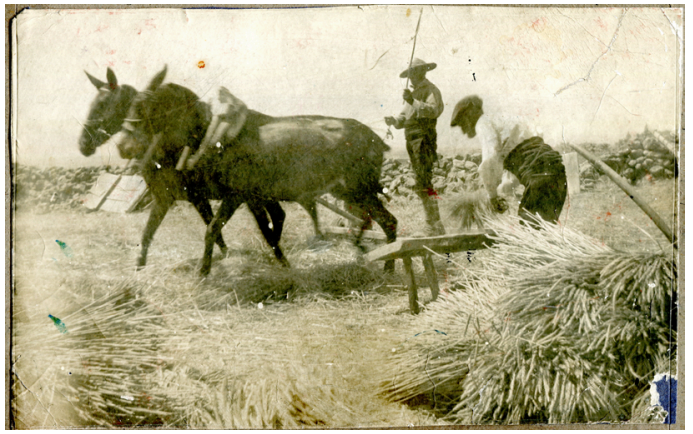

- Fig. 7. Fotografía del Archivo de Daniel Zuloaga. Archivo Daniel Zuloaga Segovia-Junta de Castilla y León.

la portada del aludido catálogo comercial reproducido al principio de este artículo, donde se aprecia la correspondiente retícula para materializar los azulejos ${ }^{35}$. Se trata de un anteproyecto del ceramista para uno de los lados largos del portal, pues en el mismo se suceden la escena de labriegos segovianos, enmarcada ya por los referidos asuntos fabriles y mineros, el subiente modernista y la composición del alto horno. No obstante, la primera y la última no coinciden exactamente con la versión definitiva, de manera que está claro que el artista barajó varias tentativas. Por lo que atañe al campo de cereal, la composición de este boceto está tomada de la fotografía conservada en el archivo particular de Zuloaga que aquí publicamos ${ }^{36}$ (Fig. 7), ahondando en su recurrente uso de ese tipo de imágenes. En cuanto a los motivos del friso que delimita el borde inferior de la escena, hay que precisar que aquí aparecen la locomotora de un tren minero y un tranvía aéreo con el correspondiente cableado, que, como queda dicho, finalmente fueron sustituidos por edificios segovianos, reforzando así la existencia de dos líneas temáticas en el primer tramo del portal. Por lo que atañe al mural del alto horno, la variación principal estriba en el primer término, ocupado por aguas fluviales en lugar de la comentada vía férrea.

\footnotetext{
${ }^{35}$ Cerámica artística..., s.p.

${ }^{36}$ ADZS, leg. 16, Fotografías de tipos populares y escenas regionalistas, sin clasificar.
} 
La solución definitiva guarda más relación con las grandes decoraciones para vestíbulos de viviendas unifamiliares diseñados por Zuloaga a principios del siglo XX que con sus revestimientos para portales de casas de vecindad. Por entonces recibió dos encargos de este tipo en Madrid por parte del arquitecto Jesús Carrasco-Muñoz Encina. El primero, destinado a la casa de la Marquesa de Eguarás (1899), situada entre las calles Barquillo y Prim, se fraguó en abril de 1900. Se trata de un recinto articulado por pilastras adosadas a las paredes, de manera que la labor cerámica se limitó a la parte superior de los entrepaños. El ceramista suministró catorce paneles de 0'80 m x 0'80 m decorados con cabezas femeninas colocadas de perfil, en las que se aprecia la ascendencia de Alfons Mucha (1860-1939) y, por ende, ecos simbolistas y modernistas ${ }^{37}$. Poco después, diseñó cuatro plafones de 0’30 m x 0’40 $\mathrm{m}$ con alegorías de las Cuatro Estaciones y otros doce de 0'20 m x 0'16 m con los signos zodiacales para el portal de la casa de Luisa de la Hoz (1900), ubicada en la plaza de Chamberí, que, a día de hoy, no se conservan, aunque a juzgar por la documentación el proyecto se materializó ${ }^{38}$.

Estas dos propuestas entrañaban un desarrollo limitado del revestimiento cerámico que, a diferencia del ejemplo bilbaíno, no cubría por completo las paredes del recinto.

${ }^{37}$ Sobre este portal vid. Quesada Martín, "Daniel Zuloaga. Ceramista y pintor...", T. II, 154-159 y Daniel Zuloaga 1852..., 116; Óscar da Rocha Aranda, El modernismo en la arquitectura madrileña. Génesis y desarrollo de una opción ecléctica (Madrid: CSIC, 2009), 200-201; Óscar da Rocha Aranda y Ricardo Muñoz Fajardo, Madrid modernista: guía de arquitectura (Madrid: Tébar, 2006), 20; Óscar da Rocha Aranda y Susana Torres Neira, Arquitectura madrileña. Del eclecticismo a la modernidad. Jesús Carrasco-Muñoz (1869-1957) (Madrid: La Librería, 2002), 60-61; Abraham Rubio Celada, “Innovaciones técnicas, estilísticas y temáticas en la cerámica de Zuloaga", Boletín de la Sociedad Española de Cerámica y Vidrio, vol 38, n4 (1999), 48.

${ }^{38}$ Quesada documentó la obra, Quesada Martín, "Daniel Zuloaga. Ceramista y pintor...", T. II, 170 y Daniel Zuloaga 1852..., 116; Da Rocha Aranda y Torres Neira, Arquitectura madrileña..., 60-61.
Así las cosas, el portal de la casa de Nicolás Murga está más próximo a las soluciones de los vestíbulos de residencias como las de Tomás Allende Alonso en Bilbao ${ }^{39}$ o la de Fernando Merino Villarino en León ${ }^{40}$, que estaban totalmente forrados con plafones cerámicos y que fueron ideados por Zuloaga hacia las mismas fechas. Las similitudes con estos recibidores se extienden a los marcos de los paneles, delimitados por formas ovaladas o curvas y orlas con motivos vegetales de ascendencia modernista, la inclusión de asuntos fabriles, mineros o agrícolas, las técnicas empleadas e incluso el tamaño de los azulejos. Pese a todo hay que hacer la salvedad de que, como hemos explicado, el portal de la casa de Nicolás Murga presenta un zócalo de mármol, acorde a lo usual en los zaguanes bilbaínos de la época, algo que sin duda fue impuesto por el promotor y Aladrén.

Desde el punto de vista técnico, cabe señalar que algunas de las escenas y figuras de este zaguán fueron materializadas con un acusado sentido pictórico a base de formas abocetadas, al tiempo que en otras se advierte una evidente simplificación de los volúmenes con frecuencia tendentes a una acusada geometría y esquematismo, rasgos que aportan modernidad. Zuloaga empleó azulejos de $18 \mathrm{~cm}$ x $18 \mathrm{~cm}$ y dos técnicas. Por un lado, la de arista, también llamada de cuenca, y, por otro, la pintura sobre esmalte. Con la primera ejecutó las serpenteantes líneas coup de fouet, los motivos vegetales y florales de marcado esquematismo y bidimensionalidad, las mariposas, las estrellas de cuatro puntas, los círculos, etc. que de-

${ }^{39}$ Edificio proyectado por Achúcarro entre 1898 y 1899, para cuyo vestíbulo Zuloaga diseñó y realizó un mural de 54 metros cuadrados en 1900. Maite Paliza Monduate, “La cerámica aplicada...", 237-260.

${ }^{40}$ Este edificio fue proyectado por Juan Crisóstomo Torbado como vivienda unifamiliar y ulteriormente se transformó en casa de vecindad. Zuloaga concluyó la decoración cerámica del vestíbulo en los últimos meses de 1902, si bien por fallos de cálculo hubo que rehacer algunos detalles en 1903. Valdés Fernández, "Una cerámica...”, 387-395 y “Un aspecto...”, 99-107. 
coran los entrepaños que deslindan los paneles principales. Igualmente en los bordes de los últimos, que también apuestan por la sinuosidad, así como en los ornamentos de ascendencia vegetal que los adornan y en algunos detalles de los frisos que delimitan las composiciones del cargadero de El Piquillo y los labriegos segovianos también se observa técnica de arista, mientras que las escenas propiamente dichas fueron ejecutadas con pintura sobre esmalte.

En este proyecto conviven detalles de ascendencia art nouveau, regionalistas y realistas, cosa que también se percibe en los mentados vestíbulos de las casas de Allende y Merino y en la mayoría de los diseños salidos del taller del ceramista en esos años. A la primera corriente corresponden las composiciones que deslindan los dos paneles de cada uno de los flancos del vestíbulo, en los que un estilizado tallo, del que nacen vástagos vegetales y flores, asciende serpenteante con el ritmo del coup de fouet. La misma impronta se percibe en las molduras que enmarcan todas las composiciones y las formas que las enriquecen. Dentro del regionalismo están los paneles que flanquean la puerta de ingreso al portal, dado su tono bucólico e incluso tópico, a la par que próximo al mundo rural, si bien su carácter abocetado es impropio de ese estilo que puso mucho énfasis en la minuciosidad para representar las indumentarias, concebidas en buena medida como una seña de identidad. Por último, los asuntos industriales son de corte realista.

La obra se remató a lo largo del primer trimestre de 1902. Todavía a principios de febrero el propietario urgía al ceramista para que mandara las piezas para así terminar definitivamente la casa ${ }^{41}$. Los azulejos fueron remitidos en los primeros días de marzo, momento en el que el artista acusó recibo de los mismos en una carta dirigida a su socio Vargas. El pedido llegó en perfecto estado a la capital vizcaína, parece que en cajas capaces de almacenar cien azulejos. No obstante,

${ }^{41}$ ADZS, leg. 3, Correspondencia 1902-1903, Carta de Murga a Zuloaga fechada el 5 de febrero de 1902.

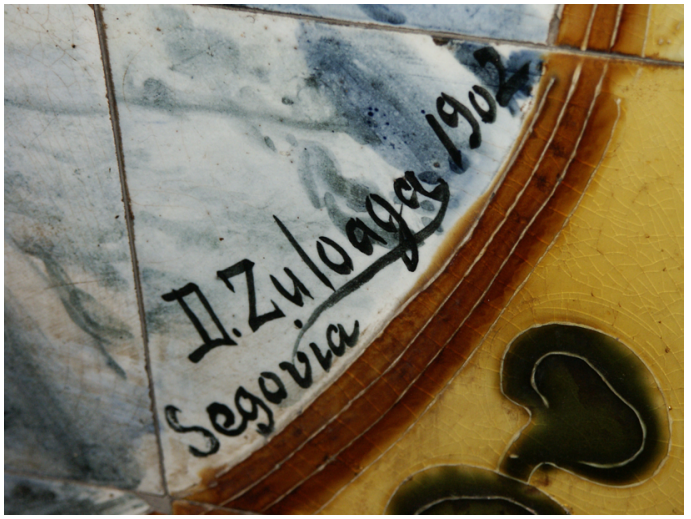

- Fig. 8. Daniel Zuloaga. Detalle del plafón del alto horno con la firma del ceramista en el portal de la casa de Nicolás Murga, calle Gardoqui no 11 (Bilbao) 1902. Foto de la autora.

Zuloaga lo consideró peligroso, por lo que dio la orden de que no volvieran a actuar así y que en lo sucesivo utilizaran paquetes más pequeños ${ }^{42}$.

El precio ascendió a 2100 pesetas, a razón de 75 pesetas el metro cuadrado, cantidad que consta en unas listas de tipo contable relativas a los encargos recibidos por el artífice a lo largo de $1901^{43}$. Otros documentos revelan que en un principio, a diferencia de su tendencia habitual, Zuloaga no había rubricado ninguno de los paneles del portal. De todos modos, finalmente lo hizo en las composiciones de los labriegos segovianos y el alto horno. Hay que aclarar que en este caso el artista estampó su firma a petición del promotor, quien así se lo pidió en una carta fechada el 20 de diciembre de 1901, para que, de cara a la posteridad, constara el nombre del artífice de la obra ${ }^{44}$, que le había satisfecho plenamente ${ }^{45}$ (Fig. 8). De hecho,

42 ADZS, leg. 3, Correspondencia 1901-1903, Carta de Zuloaga a Vargas fechada el 5 de marzo de 1902. Quesada Martín, “Daniel Zuloaga. Ceramista y pintor...", T. II, 193.

${ }^{43}$ Quesada Martín, “Daniel Zuloaga. Ceramista y pintor...", T. II, 180.

${ }^{44}$ ADZS, leg. 2, Correspondencia 1900-1901, Carta de Murga a Zuloaga fechada el 20 de diciembre de 1901.

${ }^{45}$ ADZS, leg. 3, Correspondencia 1902-1903, Carta enviada por Murga al ceramista el 24 de marzo de 1902, donde señaló que el portal era una "hermosura". 
seguidamente Murga le hizo otros encargos, en este caso piezas decorativas y vajillas, destinadas a la casa que poseía en Zuma$\mathrm{ya}^{46}$. En realidad cliente y artista se profesaron gran estima, como demuestra el hecho de que posteriormente Zuloaga se refiriera a este comitente como gran amigo y protector en una tarjeta que dirigió a su sobrino, el pintor Ignacio Zuloaga ${ }^{47}$.

En cuanto a la proyección alcanzada por este zaguán, sin ningún género de dudas el más importante entre los diseñados por el ceramista, hay que destacar que la edición bilbaína del periódico El Liberal, correspondiente al 16 de abril de 1902, incluyó un artículo monográfico sobre el mismo, que llamaba la atención de la ciudadanía sobre la calidad y el mérito de la obra ${ }^{48}$.

Zuloaga quedó también muy orgulloso de lo hecho en esta casa y pensó que podría influir en la consecución de nuevos encargos en Bilbao, aparte de incrementar su fama y prestigio $^{49}$. Su pronóstico fue acertado, pues por entonces José María Vivancos, a la sazón inquilino de Murga en el inmueble que nos ocupa y "dependiente mayor" de la citada empresa Chávarri y Cia., mostró su interés por colocar algún mural en el Teatro Campos Elíseos que estaba en construcción en la calle Bertendona ${ }^{50}$, al tiempo que otros particulares le pidieron presupuesto para distintas obras. En referencia al edificio dedicado al espectáculo, cuya fachada está engalanada con composiciones cerámicas salidas del

Quesada Martín, "Daniel Zuloaga. Ceramista y pintor...", T. II, 198.

${ }^{46}$ ADZS, leg. 3, Correspondencia 1902-1903, Cartas enviadas por Murga a Zuloaga el 2 de julio y el 27 de agosto de 1902.

47 Mariano Gómez de Caso Estrada, ed., Correspondencia de Daniel Zuloaga con su sobrino Ignacio, 26-11-2018, enlace web.

${ }^{48}$ M. E., “Una obra”.

${ }^{49}$ Quesada Martín, “Daniel Zuloaga. Ceramista y pintor...", T. II, 198.

${ }^{50}$ Quesada Martín, "Daniel Zuloaga. Ceramista y pintor...", T. II, 179. taller de Zuloaga, hay que aclarar que sus planos fueron rubricados por el arquitecto Alfredo Acebal y Gordón ${ }^{51}$ (1862-1930, titulado en 1890), aunque, como hemos adelantado, su auténtico artífice fue el mentado Darroqui, algo de lo que incluso se hicieron eco los medios de comunicación de la épo$\mathrm{ca}^{52}$. Igualmente es pertinente comentar que Acebal proyectó diversos inmuebles para la familia Allende ${ }^{53}$, por lo que también pertenecía al grupo de arquitectos estrechamente vinculado con el colectivo de industriales mencionados anteriormente, si bien en menor grado que Aladrén, Achúcarro y Darroqui.

De todos modos, aunque Zuloaga recibió pedidos importantes para Bilbao a lo largo de las dos primeras décadas del siglo XX, tardó muchos años en volver a decorar un portal en la capital vizcaína. No obstante, en ese período, concretamente en 1910, restauró el portal de la casa de Murga, como consecuencia del desprendimiento y rotura de dos azulejos. En esta ocasión, Nicolás Gracia, hijo político del promotor, contactó con el ceramista para resolver el problema, al tiempo que le pidió consejo para evitar contingencias de ese tipo. En sí misma esta

51 Acebal nació en el municipio vizcaíno de Balmaseda y cursó la carrera en la Escuela de Arquitectura de Madrid. Proyectó numerosas obras a lo largo de su trayectoria profesional, acorde a la diversidad de corrientes vigentes en esos años. En Bilbao destacan el desaparecido Frontón Euskalduna (1895), el Colegio de los Escolapios (1910) y varias casas de vecindad de corte ecléctico. Fue concejal del Ayuntamiento de la capital vizcaína, estuvo vinculado a la Escuela de Artes y Oficios de esa ciudad y durante un tiempo ejerció como arquitecto municipal de Baracaldo, donde también diseñó muchos inmuebles.

${ }^{52}$ Los promotores del edificio fueron el propio Vivancos y Luis Urizar Roelas. Los planos del inmueble están fechados en abril de 1901, pero la conclusión de las obras tuvo lugar un año después, inaugurándose en el mes de agosto de 1902. ADFB, Sección Municipal, Bilbao, leg. 5/567/1.

${ }^{53}$ Acebal diseñó en 1896 una casa de vecindad entre la calle Bailén y el Muelle de La Naja para Manuel Allende Villares. ADFB, Sección Municipal, Bilbao, leg. $4 / 202 / 1$. 
iniciativa pone de manifiesto, una vez más, la estima que los propietarios sentían por el vestíbulo $^{54}$. Finalmente, en octubre de ese año el artista volvió a hacer las piezas dañadas que quedaron instaladas sin que apenas se notara la diferencia respecto a las originales ${ }^{55}$.

En $1919^{56}$, dos años antes de su fallecimiento, recibió el encargo de decorar el zaguán de otra casa de vecindad de Bilbao. En este caso, el edificio promovido tres años antes por Armando Otero Murueta ${ }^{57}$ en la calle

${ }^{54}$ ADZS, leg. 7, Correspondencia 1910-1911, Cartas enviadas por Nicolás Gracia a Zuloaga el 16 y 19 de agosto, el 26 de octubre y el 5 de noviembre de 1910 . Quesada se hizo eco de esta intervención pero sin aclarar los detalles. Quesada Martín, Daniel Zuloaga 1852 ..., 124 y "Daniel Zuloaga. Ceramista y pintor...", T. I, 320.

${ }^{55}$ ADZS, leg. 7, Correspondencia 1910-1911, Carta de Nicolás Gracia a Zuloaga fechada el 5 de noviembre de 1910 .

${ }^{56}$ Quesada Martín, “Daniel Zuloaga. Ceramista y pintor...", T. IV, 1387-1390. La primera indicación sobre este encargo data del 18 de junio de 1919 en una carta dirigida por Bedia a Zuloaga.

57 Armando Otero Murueta (1886-1932), nacido en Bilbao, pertenecía a una familia de marinos y consignatarios de buques. Durante un tiempo vivió en el actual no 28 de la calle Hurtado de Amézaga, donde nacerían sus tres hijos mayores, el tercero de los cuales sería el poeta Blas de Otero (1916-1979). En Bilbao regentó un negocio dedicado a la importación y distribución de minerales y materiales de construcción, que, según varios indicios, contó con delegaciones en distintos puntos de la península. Durante un tiempo también tuvo intereses en el mundo de la industria conservera. En 1916 promovió la construcción de la casa de vecindad que nos ocupa, pero además era dueño de otros terrenos e inmuebles en la zona. Concluido el edificio que estudiamos en estas páginas en 1919, trasladó la sede de su empresa a los bajos del mismo.

Mediada la década de los veinte se arruinó y se trasladó a Madrid. Poco antes de la quiebra de sus negocios acometió la construcción de otra obra en el solar contiguo al del inmueble que nos atañe. En este caso el artífice fue Ignacio Smith Ibarra. Sin embargo, esta obra se limitó a la erección de los cimientos, el sótano y la planta baja, aunque el promotor tenía la intención de elevar pisos posteriormente. A partir de
Hurtado de Amézaga, al que actualmente corresponde el número 48 de esa vía. Se trata de un inmueble entre medianeras que inicialmente fue proyectado con sótano, planta baja y siete alturas, con dos viviendas por rellano ${ }^{58}$, si bien finalmente solo cuenta con cuatro pisos. El artífice del proyecto fue el arquitecto Mario Camiña Beraza (1869-1925, titulado en 1895) ${ }^{59}$, figura destacada del modernismo en Vizcaya, aunque la presente obra se enmarca dentro del regionalismo, estilo en pujanza cuando se diseñaron los

los planos sabemos que el bajo fue concebido como almacén y oficina. Los correspondientes trabajos quedaron terminados en 1924. Poco después Otero pidió autorización para abrir allí una emisora de radio, pues también fue el director gerente de S.A. Radio Vizcaya, detalle que revela que diversificó sus negocios, así como su espíritu inquieto y emprendedor.

Toda la información aportada en estas líneas procede de ADFB, Sección Municipal, Bilbao, legs. 4/535/42, 6/106/2, 6/146/21, 11bis/4/8, 6/172/676, 6/172/679 y Fomento 154/600. Sección Administrativa, legs. AX00553-008 y AX00553-008.

${ }^{58}$ Así consta en el plano firmado por el artífice del proyecto en agosto de 1916. No obstante, la licencia obtenida por el promotor en esa época fue revocada por el Ayuntamiento un año más tarde, ante la incomparecencia de Otero para recoger el permiso. Por tanto el inicio de la construcción se demoró. ADFB, Sección Municipal, Bilbao, leg. 5/319/1.

59 Camiña diseñó numerosos inmuebles modernistas, sobre todo dentro de la variante sezessionista, especialmente viviendas unifamiliares, así como algunas casas de vecindad, panteones y cementerios. En lo relativo a los portales fue artífice de uno de los más notables existentes en Bilbao de ese estilo, concretamente el de la casa de su cuñado Bernardino Hormaechea (1910) en la calle Marqués del Puerto no 10 . Ejerció además como arquitecto provincial de Vizcaya entre 1902 y 1918, cuando, por motivos de enfermedad, tuvo que abandonar la práctica profesional, y fue profesor de la Escuela de Artes y Oficios de Achuri. Entre sus obras más destacadas figuran el Cementerio de Galdácano (1904) (Vizcaya), la residencia Zabalgoitia (1906) en Arceniega (Álava), el Sanatorio Marino de Górliz (1910) (Vizcaya), el desaparecido Teatro Trueba (1912) en Bilbao, etc. Vid. una pequeña lista de proyectos modernistas de este técnico en Gorka Pérez de la Peña Oleaga, La arquitectura modernista en Bizkaia: Ismael de Gorostiza (1908-1915) (Bilbao: Diputación Foral de Bizkaia, 1993), 34. 
planos. No obstante, esta obra también es un buen ejemplo de la dificultad para diseñar casas de vecindad dentro de esa estética, a diferencia de lo que ocurría con la vivienda unifamiliar que contaba con modelos específicos tanto en la variante vasca con el caserío como en la montañesa con las casonas. De hecho, los principales detalles regionalistas de la fachada corresponden a la planta baja y se concentran en torno a los locales comerciales y la propia puerta de ingreso al portal. Concretamente se trata de las columnas y, sobre todo, las zapatas que las coronan, decoradas con el característico disco solar empleado en estelas funerarias de la zona desde tiempo inmemorial.

Este zaguán tiene planta trapezoidal ligeramente irregular y está separado de la caja de la escalera mediante una puerta acristalada de madera, precedida por dos peldaños ${ }^{60}$. En este caso el solado es de baldosa cerámica, decorada con motivos geométricos en los que dominan los tonos azules, verdes y marrones claros. El techo está acabado simulando falsas vigas de madera oscura separadas por zonas enyesadas pintadas en blanco, aunque todo ello, al igual que ocurre en el zaguán de la casa de Murga, está realizado con escayola. Se trata de un diseño frecuente en los ejemplos regionalistas y lo mismo podemos decir de la lámpara de farol que lo ilumina. A su vez el acabado de la puerta principal, que es de madera y está compuesta con casetones que enmarcan piezas romboidales, responde a soluciones al uso en dicha corriente. Todo ello, unido a la impronta popular que, como veremos, prevalece en los frisos cerámicos de inspiración goyesca, refuerza una armonía estilística.

La obra pertenece a la última etapa de la producción de Zuloaga, cuando su salud estaba un tanto debilitada y sus hijos, los también ceramistas Juan (1884-1968), Esperanza (1881-1937) y Teodora (1886-1976), jugaban un papel importante en el taller. De todos

${ }^{60} \mathrm{La}$ anchura de la entrada es 2'33 m, mientras que la puerta que delimita el paso a la zona de la escalera mide 3’30 m modos, este encargo se concretó al final de la construcción del edificio y de la documentación se desprende que la decisión de colocarlo no fue del tracista de los planos y que en la misma no medió ningún arquitecto, sino que fue una iniciativa del decorador Ismael C. Bedia, propietario de una tienda de muebles, y del propio Otero ${ }^{61}$. El interiorista corrió a cargo del amueblamiento y otros aspectos de la ornamentación del inmueble tras la retirada de Camiña del ejercicio de la profesión.

El 18 de julio de 1919 Bedia escribió a Zuloaga indicándole que el promotor quería cuatro paneles para el portal, dos grandes con "reproducciones cualquiera del Museo del Prado" y otros dos más pequeños con motivos al gusto del ceramista ${ }^{62}$. En ese momento ya estaban claras las medidas de los primeros (2'20 m x 3'50 m y 2'20 m x 2'45 $\mathrm{m})$, mientras que para los últimos se barajaban unas dimensiones distintas a las definitivas, pues la petición aludía a murales de 2'20 m x 0'75 m y 2'20 m x 0’30 m. Creemos que esta variación afectaba a la greca que, como veremos, finalmente delimitó el perímetro de las escenas goyescas y las propias puertas del recinto, pues el formato indicado para las supuestas composiciones pequeñas vendría a demostrar que en esa fecha no contaban con la faja en cuestión. Seguramente el cambio de criterio se debió al artista para realzar los plafones principales y conseguir una estancia con un revestimiento unitario. En la misiva Bedia también insistió en que

\footnotetext{
${ }^{61}$ Estaba al frente del comercio Muebles de estilo y económicos, situado en la antigua calle Estación $\mathrm{n}^{\text {o }}$ 4 de Bilbao, muy cerca de la casa de vecindad que nos ocupa. Así se desprende de la carta enviada por Bedia al ceramista en la que dejó constancia de que estaba decorando ese inmueble y que el dueño quería "un motivo decorativo en azulejo". ADZS, leg. 11, Correspondencia 1918-1919, Carta de Bedia a Zuloaga fechada el 18 de junio de 1919. Quesada Martín, “Daniel Zuloaga. Ceramista y pintor...", T. IV, 1388.

${ }^{62}$ ADZS, leg. 11, Correspondencia 1919-1920, Carta de Bedia a Zuloaga, fechada el 18 de julio de 1919.
} 
existía cierta urgencia para contar con los alicatados $^{63}$.

Poco después, el decorador se dirigió de nuevo a Zuloaga y le adjuntó un pequeño documento escrito por el promotor, donde constaban las medidas definitivas. Estas anotaciones dejan claro el cambio de criterio y que las partes implicadas habían optado por disponer una greca alrededor de los paneles grandes, pues se alude a revestimientos de $0^{\prime} 20 \mathrm{~m}, 0^{\prime} 13 \mathrm{~m}, 0^{\prime} 16 \mathrm{~m}$ y $0^{\prime} 14^{\prime} 5 \mathrm{~m}$ de anchura $^{64}$, que inequívocamente inducen a pensar en fajas.

Por lo que atañe a las escenas principales, pese a que consta que obraba en poder del artista una pequeña colección de fotografías de obras de grandes maestros de la pintura española, que incluía reproducciones de cuadros de Velázquez, Ribera, Murillo, etc. pertenecientes a dicha pinacoteca ${ }^{65}, \mathrm{Zu}$ loaga se decantó por Goya, artista que admiró profundamente ${ }^{66}$. En concreto por la serie de cartones para tapices de los años setenta y ochenta del siglo XVIII, temática que ya había tenido incidencia en su producción de piezas de arte mueble, especialmente en las dos primeras décadas de la pasada centuria, y que entronca, como queda dicho, con los postulados del regionalismo, dado el acento en lo popular y lo castizo. Se trata de diversos platos, cajas, placas, etc. decorados con copias de obras del pintor aragonés ${ }^{67}$. De todos modos, el presente artículo vendría a demostrar que esa corriente también incidió en su producción destinada a la arquitectura.

63 ADZS, leg. 11, Correspondencia 1918-1919, Carta de Bedia a Zuloaga, fechada el 14 de julio de 1919. Quesada Martín, “Daniel Zuloaga. Ceramista y pintor...", T. IV, 1388.

${ }^{64}$ ADZS, leg. 11, Correspondencia 1918-1919, Carta de Bedia a Zuloaga, fechada el 18 de julio de 1919.

${ }^{65}$ Rubio Celada, Los Zuloaga. Artistas..., 160-161.

${ }^{66}$ Fue el artista más citado en la correspondencia y escritos del ceramista. Rubio Celada, Los Zuloaga. Artistas..., 87.

${ }^{67}$ Rubio Celada, Los Zuloaga. Artistas..., 342-343.
Así las cosas, existe un paralelismo con lo hecho en los referidos años por el propio Goya, quien había optado por dar paso a una cierta conciencia nacionalista con la introducción de personajes urbanos, tipos madrileños, etc., fácilmente reconocibles por sus coetáneos, en detrimento de los asuntos y el estilo de ascendencia flamenca, acorde con las obras de David Teniers el Joven, predominantes en los tapices hasta finales de la centuria dieciochesca ${ }^{68}$.

Con independencia de la coincidencia temática con el regionalismo, lo cierto es que a partir de la segunda década del siglo $X X$ en la obra de Ignacio Zuloaga también se reflejó una manifiesta influencia del artista de Fuendetodos ${ }^{69}$. Este influjo impactó a su vez en su círculo más cercano al que, por otra parte, pertenecía el ceramista, ya que entre ambos existió una relación muy estrecha y continuada en el tiempo que, entre otras cosas, ratifica la abundante correspondencia que intercambiaron ${ }^{70}$. A su vez en 1914 Daniel realizó obras para Santiago Etxea, la casa que aquel estaba terminado de construir en Zumaya.

Tampoco es casual que poco antes de la petición de Bedia, junio de 1919, se celebró en La Lonja de Zaragoza la Exposición Hispano Francesa de Bellas Artes, en la que participaron el propio Daniel y su hijo Juan. Entonces el primero impartió allí una conferencia sobre la biografía de Goya y fue nombrado académico de la de San Luis ${ }^{71}$. Ese mismo

\footnotetext{
${ }^{68}$ Janis A. Tomlinson, Francisco de Goya: Los cartones para tapices y los comienzos de la carrera de Goya en Madrid (Madrid: Cátedra, 1993), 21.

${ }^{69}$ Con referencia a la influencia de Goya en Ignacio Zuloaga y su círculo más cercano vid. Jesús Pedro Lorente Lorente, "La pasión por Goya en Zuloaga y su círculo", Artigrama, no 25 (2010), 165-183.

${ }^{70}$ Mariano Gómez de Caso Estrada, Correspondencia de Ignacio Zuloaga con su tío Daniel (Segovia: Diputación Provincial, 2002); Gómez de Caso Estrada, Correspondencia de Daniel Zuloaga con su sobrino....

${ }^{71}$ ADZS, libro 1, 108. "Exposición Hispanofrancesa de Zaragoza. Don Daniel Zuloaga", Informaciones, 1 de junio de 1919.
} 


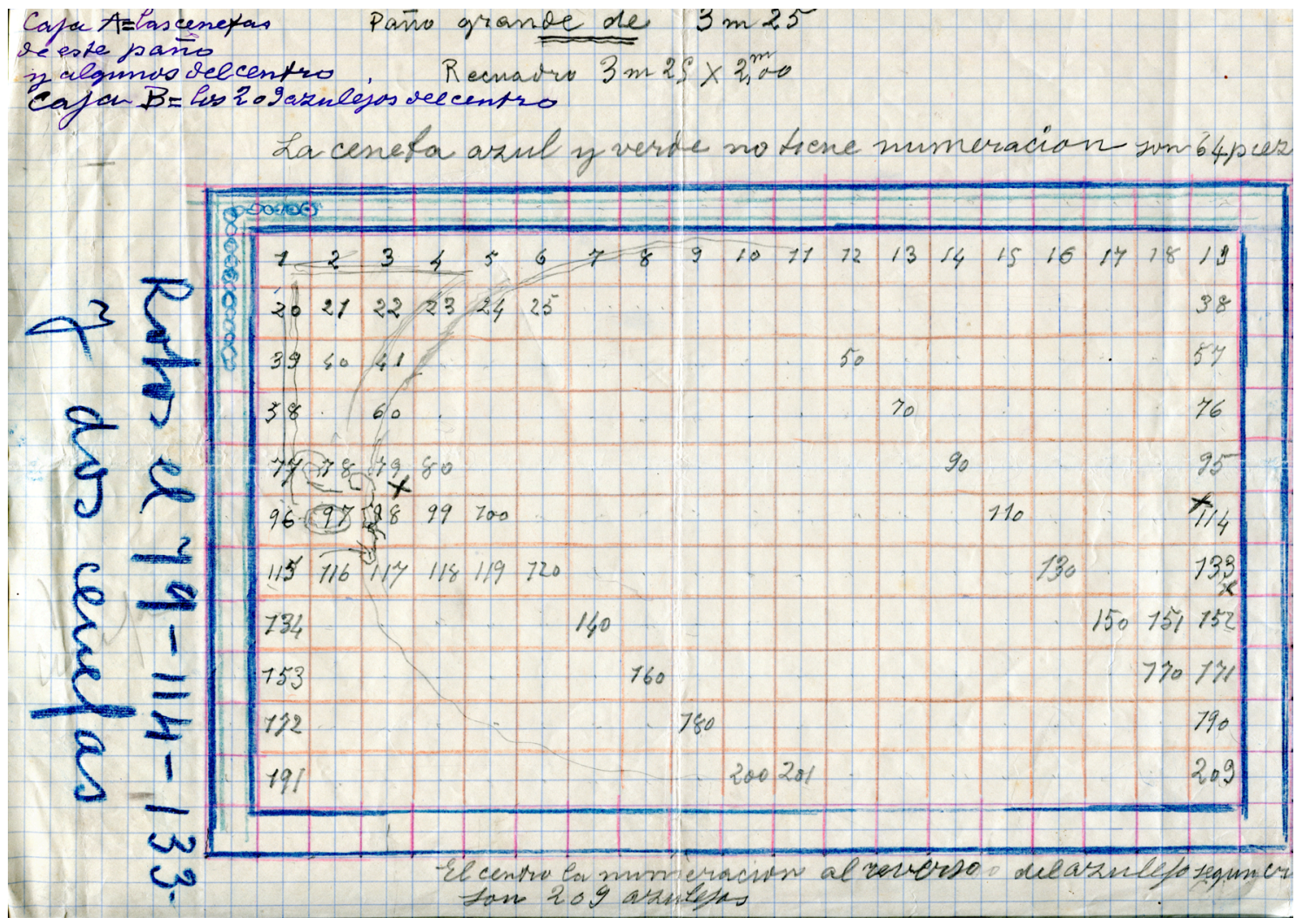

- Fig. 9. Daniel Zuloaga. Croquis para la colocación del mural El Baile de San Antonio de la Florida. 1919. Archivo Daniel Zuloaga Segovia-Junta de Castilla y León.

año, Ignacio Zuloaga fue a Burdeos (Francia) para participar en los actos del traslado de los restos del pintor aragonés a España y dos años después compró la casa natal del artista en Fuendetodos.

Zuloaga pidió 3000 pesetas "por los recuadros con La Vendimia y El Baile"72, que fueron los temas que intentó representar inicialmente. De hecho en su archivo se conservan fotografías de Jean Laurent de varios cartones de Goya preparadas con la correspondiente cuadrícula para ser copiadas en los paneles de azulejo ${ }^{73}$, sin embargo final-

72 Quesada Martín, “Daniel Zuloaga. Ceramista y pintor...", T. IV, 1387 y Daniel Zuloaga 1852..., 128. ADZS, leg. 11, Correspondencia 1918-1919, Carta de Bedia a Zuloaga fechada el 18 de junio de 1919. En esta misiva figura una anotación del ceramista que señala que pediría 3000 pesetas por El Baile y La Vendimia.

${ }^{73}$ Rubio Celada recoge lo siguiente "El Cacharrero. Fotografía 7. B/N.23 (Carpeta 13). Medidas: 28, 9 × 24, 2 $\mathrm{cm}$. Cuadriculada para ser copiada. Escrito en la parte inferior: F. GOYA. 1478. Marchand de vaiselle, carton para mente el primero fue sustituido por El cacharrero. El cambio de criterio probablemente estuvo motivado por el formato vertical de la obra desechada y por la decisión de colocar solo dos murales, uno en cada una de las paredes largas del portal. En esta ocasión el trabajo avanzó con celeridad, pues a finales de agosto de 1919 ya estaba concluido y sabemos que satisfizo plenamente al comiten$\mathrm{te}^{74}$. De cara a la instalación de los plafones y según su forma habitual de proceder, elaboró croquis con la correspondiente retícula,

tapisserie (au Musèe du Prado) J. Laurent y $C^{\underline{a}}$ Madrid / Es propiedad Dèposè. En relieve impreso J. LACOSTE MADRID. La Vendimia. Fotografía 6. B/N.16 (Carpeta 1). Medidas: 29, $5 \times 23 \mathrm{~cm}$. Cuadriculada para ser copiada". Rubio Celada, “De la tradición...”, 190.

${ }^{74}$ Quesada Martín, "Daniel Zuloaga. Ceramista y pintor...", T. IV, 1389. Bedia le transmitió a Zuloaga la satisfacción de Otero, pues el portal había quedado "muy artístico y muy fino". ADZS, leg. 11. Correspondencia 1918-1919, Carta de Bedia a Zuloaga fechada el 19 de agosto de 1919. 
donde constaba la numeración de las piezas y su ubicación para que los operarios no tuvieran problemas para colocarlas ${ }^{75}$ (Fig. 9). No obstante, cuando llegaron las cajas con los azulejos a su destino, se descubrió que cinco estaban rotos $^{76}$. Desconocemos si el artista subsanó este problema, pero en la actualidad en la banda que delimita la puerta principal se aprecian piezas que rompen con la secuencia repetitiva de las fajas. Zuloaga recibió el pago correspondiente en septiembre y parece que dio una comisión a Bedia por el encargo ${ }^{77}$.

Tanto en el plafón de El cacharrero $^{78}$ como en el de El baile ${ }^{79}$ figura la firma de Daniel Zuloaga, hecha con pasta blanca en uno de los compartimentos existentes entre las orlas interna y externa de los murales. Efectivamente los dos están enmarcados dentro de una moldura ovalada, dominada por un tono pardo verdoso-amarillento y decorada con unas estilizadas hojas, perfiladas en negro. Los extremos del eje transversal de esa faja están enfatizados por un motivo de perfil curvilíneo que enlaza con la banda que constituye el perímetro del cuadro. Se trata de un adorno recurrente en las cartelas de la época tardía de su producción, que se perpetuó en ulteriores diseños de sus hijos ${ }^{80}$. En los

${ }^{75}$ ADZS, leg. 11, Correspondencia 1918-1919, Se conservan dos croquis de este tipo de los murales del portal.

76 ADZS, leg. 11, Correspondencia 1918-1919, Carta de Bedia a Zuloaga fechada el 19 de agosto de 1919. Quesada Martín, “Daniel Zuloaga. Ceramista y pintor...", T. IV, 1389.

${ }^{77}$ ADZS, leg. 11, Correspondencia 1918-1919, Carta de Bedia a Zuloaga fechada el 21 de septiembre de 1919.

${ }^{78}$ Una fotografía de este panel apareció reproducida sin más información o comentario en Quesada Martín, “Daniel Zuloaga, ceramista...", 159.

${ }^{79}$ La diferencia de anchura entre ambos murales se debe a la presencia de una puerta en un extremo de la pared decorada con El cacharrero y al trazado irregular del vestíbulo.

${ }^{80}$ En concreto un rótulo comercial de los propios Zuloaga tiene unos motivos similares en la orla que lo enmarca. Rubio Celada, Los Zuloaga. Artistas..., 393. intersticios entre ambas molduras introdujo manchas informes, en las que se entremezclan tonos azules, carmines, verdosos, pardos, etc., sobre un fondo levemente azulado, que añaden cierto toque de modernidad.

Finalmente, los dos murales están enmarcados en todo su perímetro por una hilera de azulejos, adornados a base de motivos circulares ejecutados con gamas blanca y azul. Una solución idéntica enfatiza la superficie limítrofe con las jambas de la puerta acristalada que establece la separación con la escalera y lo mismo ocurre con la principal del zaguán.

En este caso los plafones arrancan de un pequeño basamento de mármol rosáceo de 0'33 m de altura, que actúa a modo de rodapié, de manera que los frisos cerámicos, presididos por un indudable sentido decorativo y un rico cromatismo, constituyen un elevado zócalo, que, como hemos visto, alcanza 2'20 m de altura. Los paneles no forran por completo las paredes, ya que por encima de los mismos hay una amplia franja de 1'20 m de altura pintada en tono blancuzco.

Los murales fueron ejecutados con pintura sobre baño, por tanto sin detalles de cuenca, a diferencia de lo hecho en el portal de Murga. Aquí empleó azulejos de $15 \mathrm{~cm}$ x $15 \mathrm{~cm}$, es decir más pequeños que los de aquel zaguán. En otro orden de cosas y como venía siendo usual desde tiempo atrás en su producción, los toques de color fueron conseguidos con manchas y pinceladas sueltas con una evidente simplificación de las formas, lo que se traduce en un aire un tanto abocetado, aunque con la contundencia necesaria para conseguir plasmar la escena con todos sus detalles. Así las cosas, se puede afirmar que volvió a desplegar aquí un acusado sentido pictórico.

El cacharrero fue elaborado por el genio de Fuendetodos con objeto de decorar junto a otros tapices el dormitorio de los Príncipes de Asturias en el Palacio de El Pardo, serie que ultimó entre 1778 y 1780. Representa a un hombre vendiendo piezas de vajilla a dos mujeres, mientras que una tercera de más 
edad parece que también está interesada en los útiles. Se trata de loza de "pintura de ramito" de la Fábrica de Alcora, fundada por el IX conde de Aranda en esa localidad castellonense en 1727. En concreto pertenecen a la tercera etapa de la manufactura (1786-1798), es decir que cronológicamente coinciden con el propio cartón y corresponden a los objetos más modestos salidos de allí, que en la mayoría de los casos eran comercializados por arrieros, tal como ocurre en la escena recreada por Goya ${ }^{81}$. Por lo demás, dos caballeros sentados fijan su atención en un coche, dentro del cual viaja una dama, con dos lacayos detrás del vehículo y el cochero delante. Al fondo se divisan otras figuras y algunos edificios. Por tanto, está integrado por dos grupos, en el primero algunos especialistas han querido ver una fuerte tensión sexual, lo que, unido al tema de la venta, podría conducir a una interpretación en clave de prostitución ${ }^{82}$. En el segundo, pese a estar integrado por siete figuras, sólo vemos el rostro de dos, detalle que contribuye a dirigir la atención del espectador hacia la dama que ocupa el carro. La composición resulta un tanto forzada en el caso del carruaje, cortado a la altura de los pies del conductor, de manera que apenas se intuye el tiro de caballos. A su vez la propia disposición de las ruedas demuestra cierta torpeza. Por el contrario, el cartón destaca por lo logrado de la ejecución de las mujeres del primer término y los objetos de loza, así como por la riqueza de matices de los tonos verde y rojo ${ }^{83}$.

\footnotetext{
${ }^{81}$ Sobre la cerámica de "pintura de ramito" de Alcora vid., entre otros, María Antonia Casanova, "Alcora", en Cerámica esmaltada española, coord. por Trinidad Sánchez-Pacheco (Barcelona: Labor, 1981), 151-164.

${ }^{82}$ Tomlinson, Francisco de Goya..., 116 y 117.

${ }^{83}$ Para lo relativo a esta obra de Goya vid. entre otros José Manuel Arnáiz, Francisco de Goya. Cartones y tapices (Madrid: Espasa Calpe, 1987), 95-97 y 265; Janis A. Tomlinson, Francisco de Goya; Tapices y cartones de Goya (Madrid: Patrimonio Nacional, 1996).
}

A la hora de materializar este mural ${ }^{84}$, Zuloaga reprodujo el modelo original en lo tocante a la composición, el número y el tipo de las figuras, las indumentarias, las actitudes y gestos, aunque los rostros tienen un tratamiento más somero y la factura sea especialmente suelta. Los tonos rosados que dominan en el celaje y los blancos perlados y agrisados de parte de los trajes son más intensos que en el modelo goyesco y constituyen un inequívoco homenaje al artista aragonés que utilizó mucho esas gamas (Figs. 10 y 11).

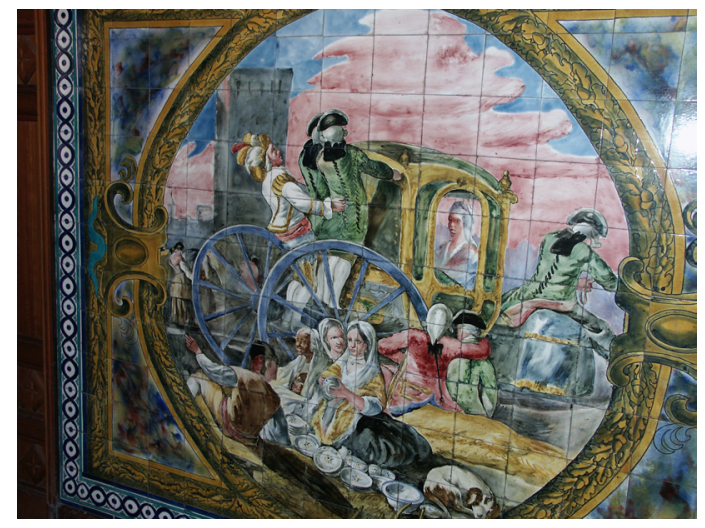

- Fig. 10. Daniel Zuloaga. Mural de El cacharrero en el portal de la casa de Armando Otero, calle Hurtado de Amézaga no 48 (Bilbao). 1919. Foto de la autora.

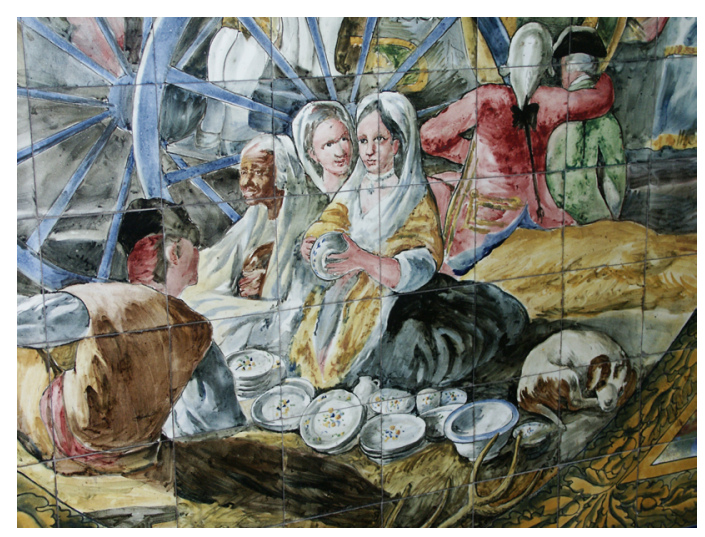

- Fig. 11. Daniel Zuloaga. Detalle del mural de El cacharrero en el portal de la casa de Armando Otero, calle Hurtado de Amézaga nº 48 (Bilbao). 1919. Foto de la autora.

84 En el archivo del ceramista se conservan fragmentos del calco a tamaño natural de este plafón. ADZS, Rollos varios sin clasificar. 
Según el propio Goya, el cartón de $E l$ baile de San Antonio de la Florida representa un baile en la ribera del Manzanares, en el que dos majos y otras tantas majas danzan seguidillas, al son de la música interpretada por otros dos jóvenes sentados a la izquierda de la composición con una guitarra y una bandurria, acompañados de otras tres figuras. Al fondo se divisan un militar y una maja en conversación y otra figura femenina, mientras que en el suelo en primer término se aprecian unas capas y unos sombreros. La escena se recorta sobre el perfil arquitectónico de Madrid, advirtiéndose el volumen de la iglesia de San Francisco el Grande, según dejó constancia el propio pintor en la factura. Este detalle permite situar la estampa que de este modo resulta más real y creíble que si careciese de referencias concretas, mientras que las construcciones del flanco opuesto pertenecen el entorno rural de aquel Madrid de finales del siglo XVIII. La composición es cerrada y claramente circular, mientras que los protagonistas bailan con una majestuosidad que parece impropia de un ritmo popular como la seguidilla. El artífice elaboró este cartón en 1777 para el comedor de los Príncipes de Asturias en el Palacio de El Pardo ${ }^{85}$.

Zuloaga fue fiel al modelo dieciochesco, ya que siguió las directrices de Goya a la hora de plasmar las indumentarias, los colores preponderantes, el tipo de fondo, etc. No obstante, todos los personajes parecen más voluminosos y menos estilizados que en el cartón, sobre todo los masculinos, mientras que el ceramista también reprodujo con bastante exactitud la disposición de las extremidades superiores e inferiores de las figuras (Fig. 12).

El portal de la casa de Armando Otero fue la última obra del artista de este género. Las diferencias con respecto al zaguán de Murga, mucho más ambicioso y grandioso, revelan la evolución experimentada por Zuloaga y su abandono del modernismo en pro del regionalismo, así como los cambios

${ }^{85}$ Sobre esta obra de Goya vid. entre otros Arnáiz, Francisco de Goya..., 72-73. sufridos por los principios decorativos en estas dependencias en la capital vizcaína. En cualquier caso es una obra de acusado sentido decorativo y de más envergadura que las de los portales diseñados para el arquitecto Carrasco-Muñoz. No tiene parangón dentro de su producción y fue uno de los grandes encargos del final de su carrera junto con los del exterior de la casa de vecindad de Tomás Allende en la Plaza de Canalejas de Madrid y los de la Cripta del Templo Nacional Expiatorio del Sagrado Corazón de Barcelona.

La relación entre Bedia y Zuloaga y la presencia del último en Bilbao continuó tras la conclusión del portal. El primero solicitó al ceramista objetos decorativos para colocarlos en el escaparate de su establecimiento, ya que consideraba que tendrían aceptación entre la clientela ${ }^{86}$. Entre el 18 y el 30 de noviembre de 1920, el artista llevó a cabo una exposición individual en la sala Majestic Hall de la Gran Vía bilbaína, que contó con buena respuesta del público ${ }^{87}$. Fue la última vez que expuso en Bilbao antes de su fallecimiento en diciembre del año siguiente.

\section{CONCLUSIONES}

La decoración cerámica de los portales de las casas de vecindad de Nicolás Murga y Armando Otero destaca sobremanera dentro de la producción de ese género de Daniel Zuloaga, dada su calidad técnica y diseño, el programa iconográfico y las dimensiones de los murales. El primero, ejecutado entre 1901 y 1902, corresponde a un momento de la trayectoria del artista en el que en su producción interactuaron el modernismo, el realismo y el regionalismo, estilos que dejaron huella en este ejemplo concreto, mien-

${ }^{86}$ ADZS, leg. 11, Correspondencia 1918-1919, Carta de Ismael Bedia a Zuloaga fechada el 19 de agosto de 1919. Quesada Martín, “Daniel Zuloaga. Ceramista y pintor...", T. IV, 1389.

87 "Crónicas de Arte. Exposición Daniel Zuloaga", La Gaceta del Norte, 23 de noviembre de 1920; "Majestic Hall. Daniel Zuloaga, el ceramista", El Pueblo Vasco, 21 de noviembre de 1920. Enrabiri, "Zuloaga, el ceramista", La Tarde, 18 de noviembre de 1920. 


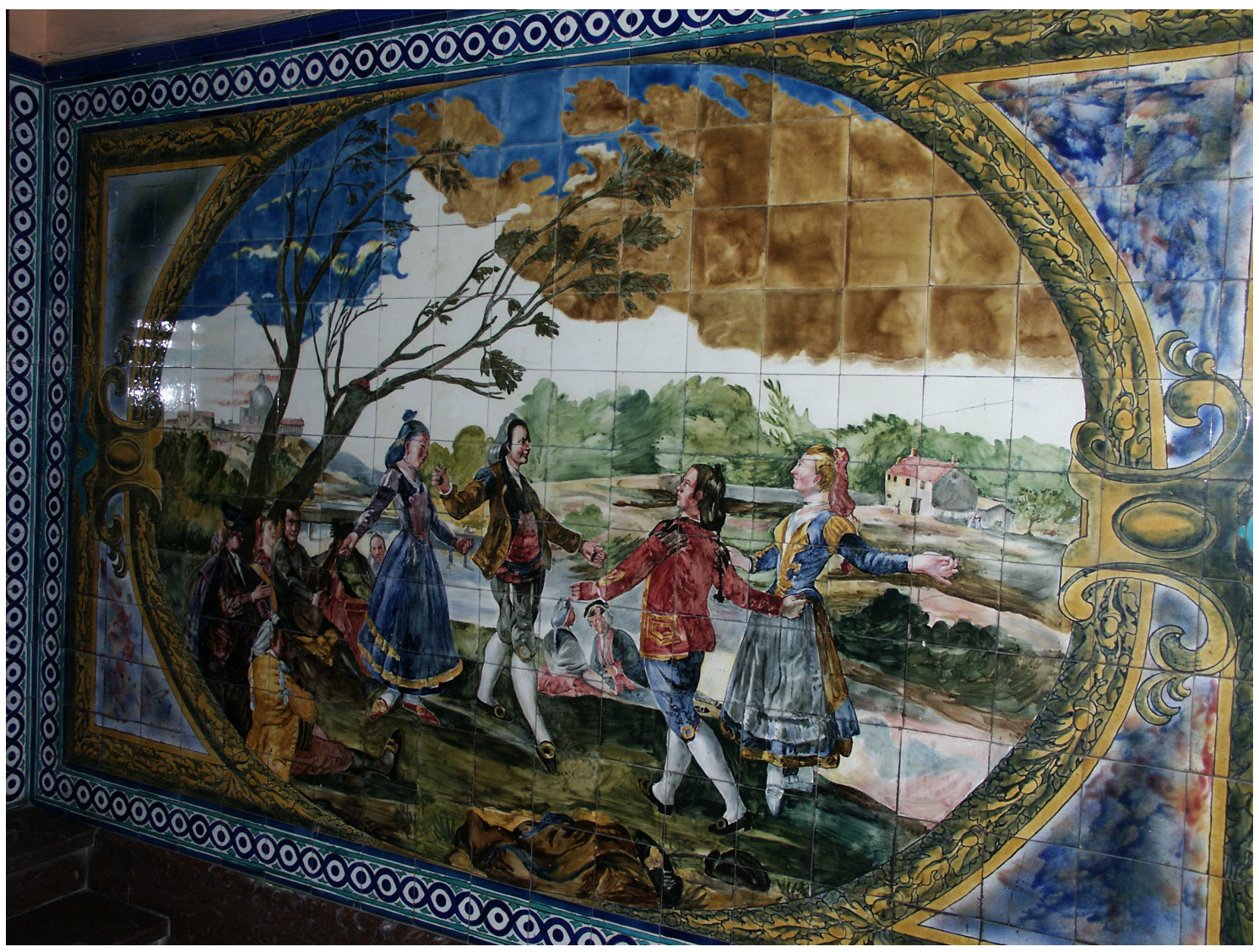

- Fig. 12. Daniel Zuloaga. Mural de El Baile de San Antonio de la Florida en el portal de la casa de Armando Otero, calle Hurtado de Amézaga no 48 (Bilbao). 1919. Foto de la autora.

tras que el segundo, realizado en 1919, deja constancia de la ascendencia de Goya sobre el ceramista, influjo que se intensificó al final de la vida de Zuloaga, fallecido en 1921, cuando el regionalismo se impuso claramente sobre las otras dos corrientes anteriormente señaladas. A su vez estos zaguanes revelan pautas habituales en la forma de trabajar del artífice, quien a la hora de diseñar este tipo de revestimientos utilizó frecuentemente fotografías, aunque introduciendo ligeras modificaciones sobre los originales en función de sus intereses. Igualmente se constata su tendencia a dibujar y pintar detalles del natural, de cara a la ulterior realización de plafones, como ocurrió en parte de los paneles del edificio de Murga, su seguimiento de las obras tanto con visitas a las mismas como con instrucciones detalladas a los operarios de su taller, los pasos de cara a los preparativos del envío e instalación de los revestimientos con la realización de los corres- pondientes croquis reticulados, en los que figuraba la numeración de los azulejos, etc.

Los dos conjuntos ponen en evidencia el papel jugado por los promotores en estos casos concretos tanto en la decisión de incorporar decoración cerámica como en la elección de parte de la temática, aparte del importante desembolso económico realizado al contratar a un ceramista tan famoso.

Se da la circunstancia de que los dos portales se encuentran en Bilbao, ciudad que experimentó un gran crecimiento urbanístico y una gran actividad constructiva a finales del siglo XIX y principios del XX y donde un buen número de arquitectos se aproximaron a la llamada arquitectura polícroma, cosa que favoreció la presencia de cerámica monumental en los inmuebles. A ese colectivo pertenecieron Luis Aladrén, Severino de Achucarro y Jean Baptiste Darroquy, vinculados de una u otra forma con el inmueble 
de Murga. Por lo demás el artículo ratifica que Zuloaga tuvo una gran aceptación en la capital vizcaína tanto en lo relativo a la cerámica aplicada a la arquitectura como en las piezas de arte mueble.

\section{BIBLIOGRAFÍA}

Alonso Olea, Eduardo José. Víctor Chávarri (1894-1900). Una biografía. San Sebastián: Eusko Ikaskuntza, 2005.

Arnáiz, José Manuel. Francisco de Goya. Cartones y tapices. Madrid: Espasa Calpe, 1987.

Casanova, María AntoniA. "Alcora". En Cerámica esmaltada española, coordinado por Trinidad Sánchez-Pacheco, 151-164. Barcelona: Labor, 1981.

“Cerámica artística para construcciones. D. Daniel Zuloaga. Segovia". En Talleres de hijos de Daniel Zuloaga - Segovia, 25, s.p. Madrid: sin editor, sin fecha.

Cerámica artística para construcciones. Segovia. Madrid: sin editor, 1904.

Correspondencia de Daniel Zuloaga con su sobrino Ignacio. http://www.museoignaciozuloaga.com/es/bibliografia.html

“Exposición Hispanofrancesa de Zaragoza. Don Daniel Zuloaga". Informaciones, 1 de junio de 1919.

Fernández Díaz-Sarabia, Pedro. El ferrocarril hullero de La Robla a Valmaseda 1890-1972. Salamanca: Junta de Castilla y León, 2003.

Gómez de Caso Estrada, Mariano. Correspondencia de Ignacio Zuloaga con su tío Daniel. Segovia: Diputación Provincial, 2002.

González Portilla, Manuel. La siderurgia vasca (1880-1901). Nuevas tecnologías, empresarios y política económica. Bilbao: Universidad del País Vasco, 1985.

Grandio, Yasmina. Urbanismo y arquitectura ecléctica en San Sebastián. 1890-1910. San Sebastián: Sociedad Guipuzcoana de Ediciones y Publicaciones, 1987.

López García-Bermejo, Ángela. El traje popular segoviano. Segovia: Caja de Ahorros y
Monte de Piedad de Segovia, 1985.

Lorente Lorente, Jesús Pedro. “La pasión por Goya en Zuloaga y su círculo". Artigrama, no 25 (2010), 165-183.

Maganto, Esther. "Los picaos en la indumentaria tradicional segoviana. Tipología, simbología y particularismos". En La palabra vestida. Indumentaria histórica y popular, 193-221. Soria: Diputación Provincial, 2015.

Maier Allende, Jorge y Abraham Rubio Celada. "La decoración de la galería de la casa de Tomás Allende en la calle Mayor de Madrid (1901). Otras obras de Daniel Zuloaga para la familia Allende". Además de: Revista on line de artes decorativas y diseño, no 2 (2016), 89-111. http://www.ademas derevista.com/numero2_articulo4.php

Mas, Elías. "Casa en Cardenal Gardoqui esquina con Bertendona". Bilbao, $\mathrm{n}^{\mathrm{o}}$ Julio (2009), 9 .

Mesuret, Geneviève y Maurice Culot. Architectures de Biarritz et de la Côte basque de la Belle Epoque aux années trent. Liège: Mardaga, 1990.

Montero, Manuel. Mineros, banqueros y navieros. Bilbao: Beitia, 1990.

Montero, Manuel. La California del hierro: las minas y la modernización económica y social de Vizcaya. Bilbao: Beitia, 1995.

Olaran, Clotilde. Palacio de la Diputación Foral de Bizkaia. Bilbao: Diputación Foral de Bizkaia, 1991.

Paliza Monduate, Maite. "La búsqueda de representatividad y distinción en los espacios comunitarios de las casas de vecindad: portales y escaleras de Bilbao 1880-1910". En Congreso Internacional Imagen y apariencia, coordinado por Concepción de la Peña Velasco y Manuel Pérez Sánchez, s.p. Murcia: Universidad de Murcia, 2009.

Paliza Monduate, Maite. “La cerámica aplicada en la decoración de interiores en torno a 1900. El mural de la casa de To- 
más Allende en Bilbao". BSAA. Arte, $\mathrm{n}^{\circ} 78$ (2012), 237-260.

Paliza Monduate, Maite. “Limitations Stemming from the Legal Regulation of Designs of Foreign Architects in Spain in the 19th Century. The Case of the Basque Country". En Nuts $\mathcal{E}$ Bolts of Construction History Culture, Technology and Society, editado por Robert Carvais, André Guillerme, Valérie Nègre y Joël Sakarovitch, T. I, 527-553. París: Picard, 2012.

Pérez de la Peña Oleaga, Gorka. La arquitectura modernista en Bizkaia: Ismael de Gorostiza (1908-1915). Bilbao: Diputación Foral de Bizkaia, 1993.

Pérez de la Peña Oleaga, Gorka. Arquitectura religiosa contemporánea en Bizkaia 18651975. Del Romanticismo al Movimiento Moderno. Bilbao: Obispado de Bilbao. 2004.

Perla, Antonio. Cerámica aplicada a la arquitectura madrileña. Madrid: TF, 1998.

Quesada Martín, María Jesús. “Daniel Zuloaga. Ceramista y pintor". Tesis doctoral. Universidad Complutense de Madrid, 1984.

Quesada Martín, María Jesús. “Daniel Zuloaga (1852-1921)". Estudios Pro Arte, no 11 (1977), 76-84.

Quesada Martín, María Jesús. Daniel Zuloaga 1852-1921. Segovia: Caja de Ahorros y Monte de Piedad de Segovia, 1985.

Quesada Martín, María Jesús. “Cerámica arquitectónica de Daniel Zuloaga en Madrid 1880-1900". Archivo Español de Arte, no 232 (1985), 369-378.

Quesada Martín, María Jesús. “Daniel Zuloaga, ceramista (1852-1921)". En Los Zuloaga. Dinastía de artistas vascos, coordinado por Ramón Suárez Zuloaga, 129-181. Usurbil: Ramón Suárez Zuloaga, 1988.

Ramos Larriba, Cipriano. Monografías de Pueblos de Bizkaia. Sestao. Bilbao: Diputación Foral de Bizkaia, 1997.

Rocha Aranda, Óscar da. El modernismo en la arquitectura madrileña. Génesis y desarro- llo de una opción ecléctica. Madrid: CSIC, 2009.

Rocha Aranda, Óscar da y Ricardo Muñoz Fajardo. Madrid modernista: guía de arquitectura. Madrid: Tébar, 2006.

Rocha Aranda, Óscar da y Susana Torres Neira. Arquitectura madrileña. Del eclecticismo a la modernidad. Jesús Carrasco-Muñoz (1869-1957). Madrid: La Librería, 2002.

Rodríguez Sorondo, María del Carmen. Arquitectura pública en la ciudad de San Sebastián (1813-1922). San Sebastián: Sociedad Guipuzcoana de Ediciones y Publicaciones, 1985.

Rubio Celada, Abraham. "Innovaciones técnicas, estilísticas y temáticas en la cerámica de Zuloaga". Boletín de la Sociedad Española de Cerámica y Vidrio, vol 38, nº 4 (1999), 48.

Rubio Celada, Abraham. "De la tradición a la modernidad: Los Zuloaga ceramistas". Tesis doctoral. Universidad Complutense de Madrid, 2004.

Rubio Celada, Abraham. Los Zuloaga: artistas de la cerámica. Madrid: TF, 2007.

Rubio Celada, Abraham y Alonso Zamora Canellada. Ocharan, Zuloaga y El Quijote. Segovia: Caja Segovia, 2007.

Tomlinson, Janis A. Francisco de Goya: Los cartones para tapices y los comienzos de la carrera de Goya en Madrid. Madrid: Cátedra, 1993.

Tomlinson, Janis A. Francisco de Goya; Tapices y cartones de Goya. Madrid: Patrimonio Nacional, 1996.

Valdés Fernández, Manuel. “Una cerámica de Zuloaga en León". En Estudios Humanísticos y Jurídicos: homenaje a Emilio Hurtado Llamas, 387-395. León: Colegio Universitario de León, 1977.

Valdés Fernández, Manuel. “Un aspecto del modernismo leonés: las cerámicas de Zuloaga". Estudios Humanísticos. Geografía, Historia, Arte, no 2 (1980), 99-107. 